ISSN: 0514-7336 — ISSN electrónico: 2386-3943

DOI: https://doi.org/10.14201/zephyrus2021881540

\title{
NUEVAS EVIDENCIAS DE ARTE RUPESTRE POSTPALEOLÍTICO EN LAS MERINDADES (BURGOS)
}

\section{New Evidences of Post-Palaeolithic Rock Art in Las Merindades (Burgos)}

\author{
Eduardo Sainz-Maza*, Diego Garate Maidagan ${ }^{* *}$ y Alejandro García Moreno** \\ * Dpto. de Ciencias Históricas. Facultad de Filosofía y Letras. Univ. de Cantabria. Edificio Interfacultativo. Avda. \\ de los Castros, 52. 39005 Santander. Correo-e: eduardosmsm@hotmail.com. ID ORCID: https://orcid.org/0000- \\ 0002-4591-141X \\ ** Instituto Internacional de Investigaciones Prehistóricas de Cantabria. Gobierno de Cantabria-Univ. de \\ Cantabria. Avda. de los Castros, 52. 39005 Santander. Correo-e: diego.garate@unican.es; alejandro.garcia@ \\ unican.es. ID ORCID: https://orcid.org/0000-0001-6685-9588; https://orcid.org/0000-0003-4861-7774
}

Recepción: 12/07/2021; Revisión: 20/09/2021; Aceptación: 8/11/2021

Resumen: El no de Las Merindades, Burgos, era un área con poca presencia de Arte Rupestre Postpaleolítico, a diferencia de otras zonas de la parte meridional de la Cordillera Cantábrica, como la vecina comarca de Campoo-Los Valles, Cantabria, y del Complejo Kárstico de Ojo Guareńa, en Merindad de Sotoscueva, Burgos, pese a compartir unas características geográficas similares. Así, el principal objetivo de nuestra investigación ha estado encaminado a resolver dicha carencia. Para ello, se ha empleado como método una prospección intensiva, centrada en una serie de áreas definidas a partir de un modelo predictivo de potencialidad arqueológica, creado mediante la aplicación de Sistemas de Información Geográfica-SIG-. Como resultado de ello, se documentaron 14 nuevas estaciones de arte rupestre al aire libre, atribuibles al periodo de la Prehistoria Reciente, las cuales vendrían a sumarse a las 5 estaciones de esta cronología ya conocidas en el sector estudiado. Esto convierte al Alto Ebro en una de las regiones con una mayor concentración de arte postpaleolítico de la Península Ibérica.

Palabras clave: Arte Rupestre; Prehistoria Reciente; Las Merindades; N de Burgos; Cordillera Cantábrica; Alto Ebro.

Aвstract: The NW of Las Merindades, Burgos, was an area with little presence of post-palaeolithic rock art, unlike other areas in the southern part of the Cordillera Cantábrica, such as the neighbouring region of Campoo-Los Valles, Cantabria, and the Karst Complex of Ojo Guareña, in Merindad de Sotoscueva, Burgos, despite sharing similar geographical characteristics with both places. Thus, the main objective of our research was aimed at solving this lack. For this, an intensive survey was used as a method, focused on a series of areas defined from a predictive model of archaeological potentiality, created through the application of Geographic Information Systems -GIS-. As a result, 14 new open-air rock art stations were documented, attributable to the recent prehistoric period, which would be added to the 5 stations of this chronology already known in the studied sector. This makes the Alto Ebro one of the regions with the highest concentration of post-Palaeolithic art in the Iberian Peninsula.

Key words: Rock Art; Late Prehistory; Las Merindades; N of Burgos; Cantabrian Mountain Range; Alto Ebro.

Ediciones Universidad de Salamanca / @oge

Zephyrus, LXXXVIII, julio-diciembre 2021, 15-40 


\section{Introducción ${ }^{1}$}

El estudio del arte rupestre postpaleolítico en la Cordillera Cantábrica ${ }^{2}$ ha tenido tradicionalmente un desarrollo escaso. Probablemente esto se ha debido al ensombrecimiento provocado por la espectacularidad y relevancia del arte paleolítico cantábrico, el cual ha centrado la atención desde los orígenes de la investigación, dejando en un segundo plano las muestras de periodos posteriores. Sin embargo, hasta el momento existían dos áreas que presentaban una mayor densidad de hallazgos en el Alto $\mathrm{Ebro}^{3}$, como son las cuevas de Ojo Guareña, en Merindad de Sotoscueva, Burgos, y la comarca de Campoo-Los Valles, Cantabria. Esto contrastaba con el No de la provincia de Burgos, situado entre ambas zonas, donde tan solo se conocían unas pocas estaciones de arte rupestre al aire libre. Pese a todo,

1 Este trabajo no hubiera sido posible sin el asesoramiento y apoyo logístico ofrecido desde la Univ. de Cantabria y el Instituto Internacional de Investigaciones Prehistóricas de Cantabria (IIIPC). Igualmente debemos agradecer la ayuda generosa como informantes del Grupo de Arqueología 'Antxieta' de Azpeitia (Guipúzcoa), del arqueólogo A. Martínez Velasco, de D. Pantano de Cabañas de Virtus, de S. Pérez de Pedrosa de Valdeporres, de E. Rodrigo de Valderredible y de la escritora E. Rivero. Este trabajo (EXPTE.: 20/177-BU) ha sido financiado por la Excma. Diputación Provincial de Burgos y los ayuntamientos de Alfoz de Bricia, Alfoz de Santa Gadea, Merindad de Valdeporres y Valle de Valdebezana. Hacemos extensible el agradecimiento a cada uno de sus empleados y representantes públicos que han facilitado nuestra labor.

2 Sistema montañoso paralelo al mar Cantábrico, el cual se extiende desde el Macizo Galaico-Leonés hasta la Depresión Vasca. Se prolonga a lo largo de cerca de $500 \mathrm{~km}$ y queda comprendido en las comunidades autónomas de Asturias, Cantabria, País Vasco, el $\mathrm{N}$ de Castilla y León, y una pequeña extensión de La Rioja y Navarra. Utilizaremos este término para referirnos de manera amplia a toda esta región montañosa.

3 Sector de la vertiente meridional de la Cordillera Cantábrica circunscrito a la cabecera de la cuenca hidrográfica del río Ebro y que comprende una porción de la comarca de Campoo-Los Valles en Cantabria y del municipio de Berzosilla en Palencia, así como la totalidad de la comarca de Las Merindades en Burgos. Usaremos esta expresión para aludir de forma local al sector meridional de la Cordillera Cantábrica en el que se ubica nuestra zona de estudio. los indicios que suponían estos escasos hallazgos, unidos a los rasgos geomorfológicos innegables que comparten las mencionadas áreas, eran señales que llevaban a plantear la problemática de que el 'vacío' de este tipo de representaciones en el no de Burgos pudiera deberse a una carencia de tradición investigadora sobre esta temática.

Encaminada a resolver dicha cuestión, se llevó a cabo una prospección intensiva de la zona de estudio, basada en un modelo de potencialidad arqueológica creado mediante Sistemas de Información Geográfica -SIG-. El desarrollo de los trabajos, autorizados por la Junta de Castilla y León, ha permitido catalogar 14 nuevos lugares con manifestaciones de arte rupestre atribuibles a la Prehistoria Reciente en el no de la provincia de Burgos, que se suman a los 5 ya conocidos. Debemos reseñar también el hallazgo de muestras artísticas posteriores, situadas entre el Medievo y la época contemporánea, las cuales no son objeto del presente estudio. Mediante el presente trabajo damos a conocer las nuevas estaciones localizadas, así como su aportación general al fenómeno gráfico durante la Prehistoria Reciente del $\mathrm{N}$ peninsular.

\section{Marco geográfico}

La zona de estudio se localiza en el extremo $\mathrm{N}$ de la provincia de Burgos, en la comarca de Las Merindades (Fig. 1). Es en el no de esta comarca donde se ubican los municipios de Alfoz de Bricia, Alfoz de Santa Gadea, Merindad de Valdeporres y Valle de Valdebezana, en los que se ha centrado el trabajo de campo. Estos lindan al N y o con la comunidad autónoma de Cantabria, al E con la Merindad de Sotoscueva y al $s$ con otros municipios burgaleses que integran la citada comarca. Los cuatro municipios cuentan con una superficie total de $363 \mathrm{~km}^{2}$, mientras que sus altitudes oscilan entre los 644 y los 1462 $\mathrm{msnm}$. Su paisaje se caracteriza por una orografía en general suave y poco accidentada (Pérez et al., 2011: 26). Se trata, por tanto, de un relieve ligeramente alomado en el que se integran algunos cerros testigo, y que aparece generado por el distinto grado de 


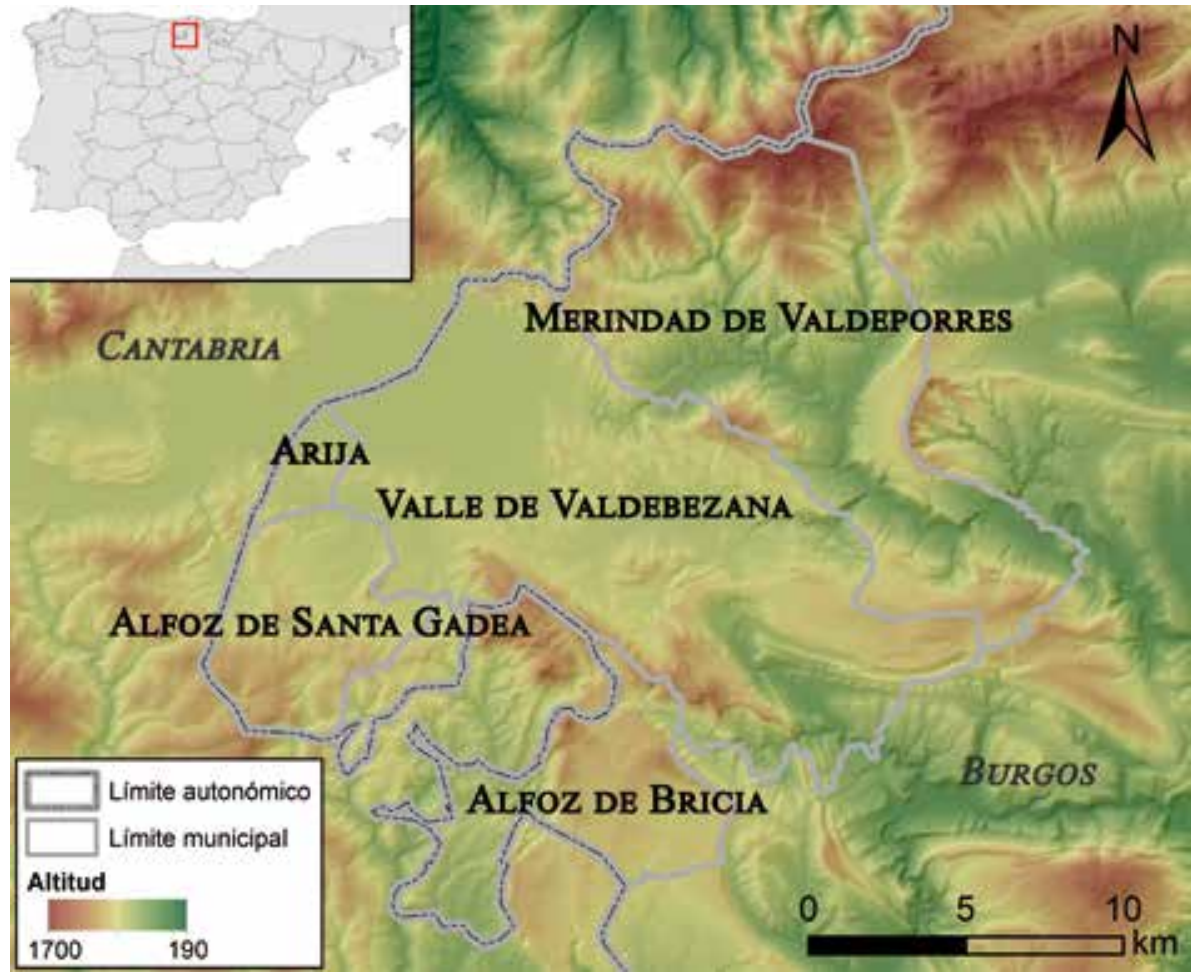

FIG. 1. Zona de estudio.

que, al igual que en el resto de lugares, quedan al descubierto debido a la acción erosiva de los ríos Nela y Engaña, así como de sus arroyos subsidiarios, creando auténticos barrancos. Estos factores han dado lugar a grandes paredes y abrigos de distinto tamaño. La principal diferencia paisajística se encuentra en el sureste de la zona de estudio, la cual viene marcada por un potente banco calizo del Turolense Superior, de unos 80-100 $\mathrm{m}$ de espesor, que trascurre de forma continua en dirección E-O entre el alto de Bedón y Valdeporres (Ortega, 1974: 47-48). Es precisamente en el interior de

resistencia a la erosión que han ofrecido las arcillas y areniscas del Cretácico Inferior predominantes en la zona. Muchas de las lomas se han visto labradas por numerosos cursos fluviales transversales que han roto el perfil general del relieve y han dejado al descubierto los estratos de arenisca, tras haber horadado los paquetes arcillosos infrayacentes que se encontraban en contacto con los mismos (Teira y Ontañón, 1997: 569). Este es un paisaje que, en su avance hacia la zona más oriental, irá introduciendo una serie de modificaciones. La primera de ellas viene marcada por el arranque de la estribación de los Montes de Somo, una gran bóveda anticlinal que supone la divisoria de aguas entre la cuenca cantábrica y la cuenca del Ebro, y que a su vez constituye el límite político entre las provincias de Burgos y Cantabria. En este lugar podemos encontrar las mayores altitudes, cercanas a los $1500 \mathrm{msnm}$, las cuales introducen un relieve ligeramente más accidentado que en la zona occidental. Pese a ello, se produce una continuación de paquetes de arenas y arcillas este gran macizo de roca caliza donde se ubica el Complejo Kárstico de Ojo Guareña.

\section{Estado de la cuestión}

Las primeras referencias al arte postpaleolítico en la Cordillera Cantábrica serán señaladas a principios del s. xx en la obra Les Cavernes de la Région Cantabrique (1911), en la cual aparecerán citadas una serie de figuras antropomorfas pintadas en la entrada de la cueva de El Castillo, en Puente Viesgo, Cantabria. Sus autores argumentarían que dichas manifestaciones no se ajustaban a los ejemplos paleolíticos del interior de la cueva, apuntando, por tanto, hacia una cronología más tardía (Alcalde del Río et al., 1911: 193).

En la década siguiente, Carballo documentará una serie de figuras grabadas en Cabrojo, Cabezón de la Sal, Cantabria. Rápidamente las pondrá en relación con los petroglifos gallegos, considerando 
la pertenencia del conjunto al Neolítico (Carballo, 1921: 350). Años más tarde, el mismo autor ampliará el número de figuras en Cabrojo y dará noticias de un lugar de similares características en la cueva de la Cańuela, en Arredondo, Cantabria (Carballo, 1936: 21-23).

En 1933, Breuil hará un repaso nuevamente a los antropomorfos de la cueva de El Castillo, y señalará la presencia de algunos signos esquemáticos que desentonaban con la apariencia paleolítica de los conjuntos de las cuevas de Las Aguas, en Novales, Cantabria; La Meaza, en Comillas, Cantabria, o El Pindal, en Pimiango, Asturias. Igualmente, realizará una somera descripción de Peña Tú, en Llanes, Asturias, y presentará de forma inédita la cueva de Los Burros, en Camasobres, Palencia, esta última ya en la vertiente meridional de la Cordillera Cantábrica. Situará todas estas grafías en momentos neolíticos y comienzos de la metalurgia (Breuil, 1933: 37-42).

La investigación recibe un impulso en los años 50 del s. xx gracias al descubrimiento del karst de Ojo Guareña, en Merindad de Sotoscueva, Burgos, que aportará un conjunto notable de representaciones artísticas postpaleolíticas. El estudio continuado de sus cavidades a lo largo de varias décadas proporcionará una amplia lista de sectores de este periodo, como son: la Galería de los Grabados (1956), la Galería Macarroni (1959), la Sala de la Fuente (1959), Cueva de Cubía (1959), la Sala Cartón (1968), Cueva de Kaite (1969), la Galería del Chipichondo (1969), Cueva La Mina (1977), la Gran Diagonal (1986) y la Sima Villallana (2003). Todos ellos cuentan con figuras o trazos atribuidos a la Prehistoria Reciente (Ortega y Martín Merino, 2013: 331-389).

En los años 80, se localizarán una laja y una estela decorada en el Collado de Sejos, Polaciones, Cantabria (Bueno, 1982: 342-348), y sendas representaciones en el Redular y el abrigo del Cubular, en Ruanales, Cantabria (Díaz Casado, 1993: 15). Además, en estos momentos se iniciará la revisión del conjunto de Cabrojo (De Balbín et al., 1983: 93-104) y comenzará el estudio de la cueva de la Peñona, en Villaescusa, Cantabria (González y Puente, 1991: 315-321).

Ediciones Universidad de Salamanca / @ه্త
Los primeros estudios de conjunto del arte rupestre postpaleolítico de ciertos sectores de la Cordillera Cantábrica no verán la luz hasta mediados de los años 80 del s. xx. El primero de ellos lo realizará Rincón (1985), y quedará reducido tan solo a la Comunidad Autónoma de Cantabria, mientras que un año más tarde González Sáinz y González Morales (1986) esbozarán un pequeño resumen de la situación en la que se encuentra el arte esquemático en dicha provincia. De manera simultánea, Ortega y Martín Merino (1986: 331-389) realizarán el primer estudio de conjunto en Ojo Guareńa.

De Balbín Behrmann (1989) llevará a cabo un estado de la cuestión que recogerá solamente la Cornisa Cantábrica, pero sin tener en cuenta la parte meridional de la cordillera. En este trabajo hará un repaso de todas las manifestaciones, sin entrar a realizar una valoración crítica de la autenticidad de muchas de ellas. Esto es algo que tratará de resolver Díaz Casado (1993), realizando una revisión crítica de nueve lugares que, para la autora, presentaban hasta ese momento un 'arte esquemático clásico' en Cantabria. En su obra recoge el primer y único estado de la cuestión, hasta el momento, que engloba a lugares de toda la Cordillera Cantábrica.

Apenas cuatro años después, Teira y Ontañón abordarán el único estudio directo que se ha realizado sobre la zona en la que se ha desarrollado nuestra investigación. Estos autores recopilaron seis lugares: Peña Lostroso, en Las Rozas de Valdearroyo, Cantabria; Portillo Viejo I y II, Peñas de la Cernolica, Corral del Barrio Abajo y Portillo de Higón, en Alfoz de Santa Gadea, Burgos. Destacará la identificación de un nuevo conjunto estilístico, como es el caso del grupo de antropomorfos de tipo 'Monte Hijedo’ (Teira y Ontañón, 1997: 569-578). A este grupo se unirá en 2007 el hallazgo de la estatua-estela de Salcedo, que comparte la misma temática, pero tratándose de una figura de bulto redondo (Teira y Ontañón, 2016a: 44-51).

La obra más reciente y única que ha abordado el fenómeno en toda su magnitud geográfica es Después de Altamira. Arte y grafismo rupestre postpaleolítico en Cantabria (Serna et al., 2016). Este trabajo constituye un catálogo de la totalidad de 
lugares de los que se tenía constancia en Cantabria, así como de las zonas limítrofes de Asturias, Palencia y Burgos. Pese a ciertos errores de interpretación y algunas cronologías forzadas ${ }^{4}$, la compilación supone un hito como punto de arranque para estudios posteriores.

En definitiva, el arte rupestre postpaleolítico sufre de una carencia de estudios de conjunto en la Cordillera Cantábrica, así como una falta de revisión crítica de las muestras de arte existentes que permita avanzar hacia una periodización precisa. Además, encontramos hallazgos por lo general muy dispersos en el terreno, debido quizás a un desequilibrio en el trabajo de campo. Es por ello que el principal objetivo marcado durante las actuaciones desarrolladas en el $\mathrm{N}$ de Burgos ha sido la resolución del vacío de estaciones al aire libre con arte rupestre postpaleolítico en el sector del Alto Ebro.

\section{Metodología}

Para resolver el objetivo marcado, se procedió a realizar una prospección sistemática de cada una de las rocas, abrigos o farallones existentes en una serie de áreas de prospección establecidas. En concreto se desarrolló una intervención de tipo intensivo (García Sanjuán, 2004: 185-210) centrada en una serie de áreas definidas a partir de un modelo predictivo

4 Es el caso del 'Dolmen' de Busnela o Covato de la Llana, lugar en el que se identifican como chevrons trazos que hemos podido comprobar que se unen a grafías de inscripciones contemporáneas. Estas figuras suponían para los autores un refuerzo del carácter megalítico de la estructura. Sin embargo, no es posible atribuir las grafías a momentos prehistóricos, como tampoco es posible atribuir a esta estructura un carácter megalítico como tradicionalmente se venía seńalando (Moreno Gallo et al., 2020). Algo similar ocurre con el abrigo de Combroz, en el cual se identifican en esta obra una serie de fusiformes que se atribuyen a la Prehistoria; sin embargo, estas figuras no son tal, sino que se trata de una disolución natural de la roca arenisca que descarta su carácter antrópico y por tanto su cronología prehistórica. Cf. Sainz-Maza, E.: Estudio sobre los patrones de distribución del arte rupestre postpaleolitico en el noroeste de Burgos: prospección y análisis espacial. Trabajo Fin de Máster inédito presentado en 2020 en la Univ. de Cantabria. de potencialidad arqueológica, creado mediante la aplicación de Sistemas de Información Geográfica -sIG-. Este modelo se basó en la observación concienzuda de cada una de las estaciones postpaleolíticas al aire libre ya conocidas y publicadas en el $\mathrm{N}$ de Burgos y en el sur de Cantabria. Del proceso de observación se lograron extraer una serie de variables cuantificables mediante SIG, como son la distancia a las corrientes de agua, tipo de litología, clasificación por tipos de terreno basado en el Índice de Posición Topográfica -TPI-, la orientación o la altitud absoluta y relativa -sobre el fondo de valle-. El análisis de estas variables para el conjunto de estaciones con arte rupestre postpaleolítico ya conocidas permitió identificar cuáles de ellas eran indicativas para explicar la distribución espacial de la muestra ${ }^{5}$. La distancia a las corrientes de agua y el tipo de litología resultaron ser variables muy indicativas, mientras que el tipo de terreno y la orientación fueron indicativas. Por su parte, la altitud absoluta y relativa resultaron no ser indicativas para la presencia de arte rupestre postpaleolítico.

Para la creación del modelo predictivo se empleó el método de valores ponderados (Ebert, 2004), consistente en otorgar un valor -'peso'- a cada variable en función de su relevancia para explicar la distribución de la muestra conocida. Así pues, las variables más indicativas recibían valores más altos y viceversa. La suma total de valores de todas las variables, extrapolada a la zona de estudio del $\mathrm{N}$ de la provincia de Burgos, tuvo como resultado un modelo cartográfico en el que se resaltaban aquellas áreas con una mayor probabilidad de albergar representaciones de arte rupestre postpaleolítico.

A partir del modelo predictivo, se definieron cinco áreas de prospección arqueológica, incluyendo tres de alta potencialidad y dos de baja potencialidad, con el objetivo de comprobar la validez del modelo ${ }^{6}$. La prospección arqueológica de campo se llevó a cabo a lo largo de una veintena de jornadas, abarcando una superficie total de $20 \mathrm{~km}^{2}$ (Fig. 2).

Para la documentación de las muestras artísticas se procedió a hacer una exploración visual detallada

5 Sainz-Maza, op. cit. n. 4.

6 Sainz-Maza, op. cit. n. 4. 


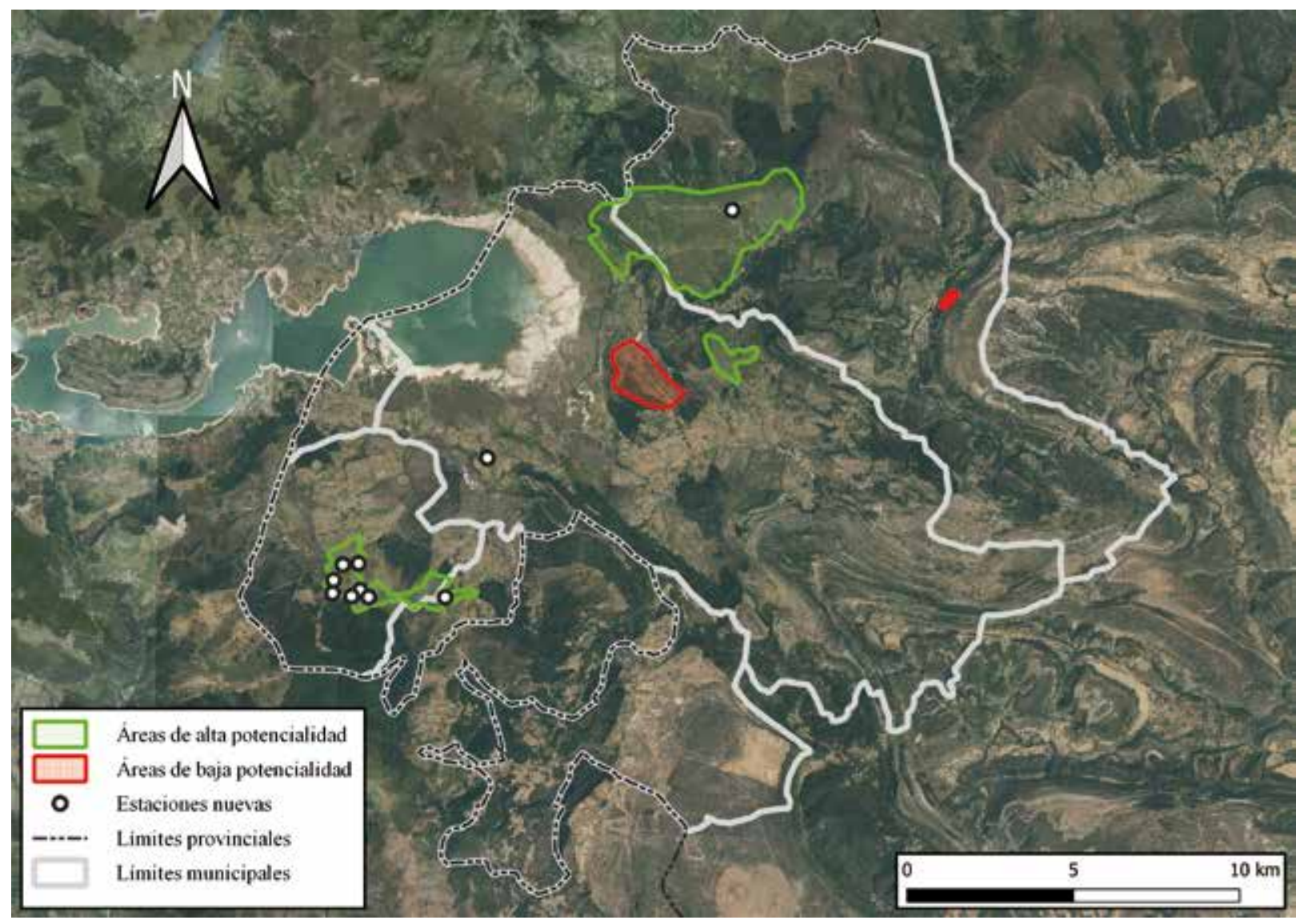

Fig. 2. Áreas de prospección.

de los soportes y de los restos presentes en los mismos, tomando datos morfométricos, coordenadas UTM, toma de imágenes, levantamientos fotogramétricos de los lugares que así lo requerían, etc. Igualmente se tomaron otros datos relevantes como el estado de conservación de los soportes, su material, orientación, relación con el entorno, etc. Todas estas referencias fueron incorporadas a una base de datos que permitiese poder acceder de manera clara y ordenada a esa información para futuros estudios.

\section{Resultados: nuevas estaciones con Arte Rupestre Postpaleolítico}

La prospección intensiva desarrollada en la zona de estudio permitió documentar 14 nuevas estaciones, frente a las 5 que ya se conocían con anterioridad. Todas las estaciones se sitúan dentro de las zonas de alta potencialidad, lo que indica la validez del modelo predictivo al no haberse encontrado ninguna en las dos zonas de baja potencialidad prospectadas (Fig. 2) ${ }^{7}$.

Para la exposición de las nuevas evidencias, seguiremos el orden numérico establecido en el mapa (Fig. 3), en el que se sigue un criterio geográfico de $\mathrm{E}$ a O y de $\mathrm{N}$ a S, alternando tanto técnicas pictóricas como de grabado.

7 El único lugar localizado fuera de las zonas de prospección ha sido el Altar de Herbosa, dado que su descubrimiento fue gracias a la información de D. Pantano. Pese a ello, cabe señalar que se localizaba igualmente en una zona de alta potencialidad. 
Postpaleolitico en Las Merindades (Burgos)

\subsection{Abrigo de Bustasabina, en Ahedo de las Pueblas-Merindad de Valdeporres}

Se trata de un pequeño abrigo de roca arenisca muy erosionada, de unos $3 \mathrm{~m}$ de longitud y unos $2 \mathrm{~m}$ de profundidad, que cuenta con un techo que va descendiendo desde los $2 \mathrm{~m}$ de altura en la boca hasta los aproximadamente $70 \mathrm{~cm}$ en el fondo. Se localiza en el nacimiento del arroyo de Bustasabina, orientado hacia el s, desde donde se puede dominar visualmente el valle de dicho arroyo sobre Ahedo de las Pueblas y la cabecera del río Nela. Muy cercano, apenas $200 \mathrm{~m}$ al o, se localiza el dolmen de Ahedo.

$\mathrm{Su}$ techo alberga un panel de $15 \times 12 \mathrm{~cm}$ compuesto por tres trazos rojos verticales de distinto tamaño. El primero de ellos, de izquierda a derecha, tiene una longitud aproximada de $4 \mathrm{~cm}$, el trazo central $12 \mathrm{~cm}$ y el situado más a la derecha $5 \mathrm{~cm}$. En el caso del trazo central es difícil concretar si se trata de un solo trazo más grueso o si se trata de dos trazos subparalelos unidos entre sí. Unos $15 \mathrm{~cm}$ a la derecha se localizan más restos de pintura, lo cual podría ser indicativo de la existencia en origen de más muestras de arte afectadas por la notable erosión del soporte (Fig. 15a).

\subsection{Altar de Herbosa, en Herbosa-Valle de Valdebezana}

Nos encontramos ante un pequeño afloramiento de roca arenisca con una forma ligeramente ovoide

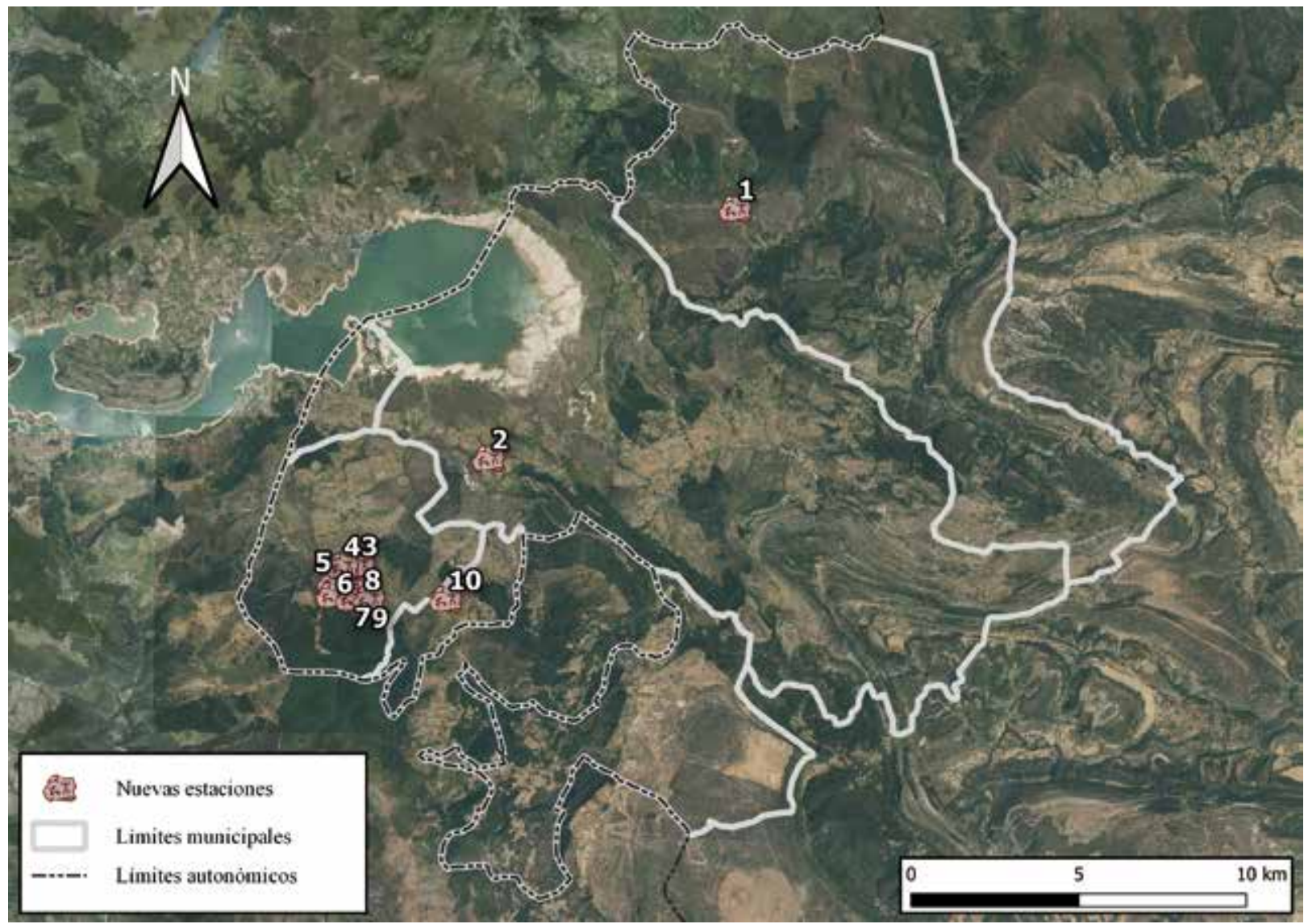

Fig. 3. Nuevas estaciones: 1) Abrigo de Bustasabina; 2) Altar de Herbosa; 3) El Castillo I y II; 4) Orantes de Santa Gadea I, II y III; 5) Abrigo de Dujos Altos; 6) Peñas Rotas I, II y III; 7) Abrigo del Perro; 8) Jinetes de la Cernolica; 9) Corral del Barrio Abajo; 10) Orantes de La Zapata. 
vista en planta. Sus medidas aproximadas son de 10 $\mathrm{m}$ de largo y $9 \mathrm{~m}$ de ancho, mientras que cuenta con una altura máxima, en su cara sur, de algo más de 2 $\mathrm{m}$. Se localiza en una finca situada en el paraje denominado 'Los Soterradores', apenas $0,5 \mathrm{~km}$ al s del casco urbano de Herbosa. Junto a esta roca discurre un pequeño arroyo, subsidiario del río Nava, el cual desemboca $5 \mathrm{~km}$ después en el embalse del Ebro. El lugar cuenta con un contacto visual directo con el Pico Nava y con el entorno de la llanada de La Virga, hoy en día ocupada por el citado embalse, lugares ambos donde existen ciertos indicios de una ocupación humana durante la Prehistoria Reciente (Bohigas et al., 1984: 7-91; Peralta, 2000; Fraile, 2004).
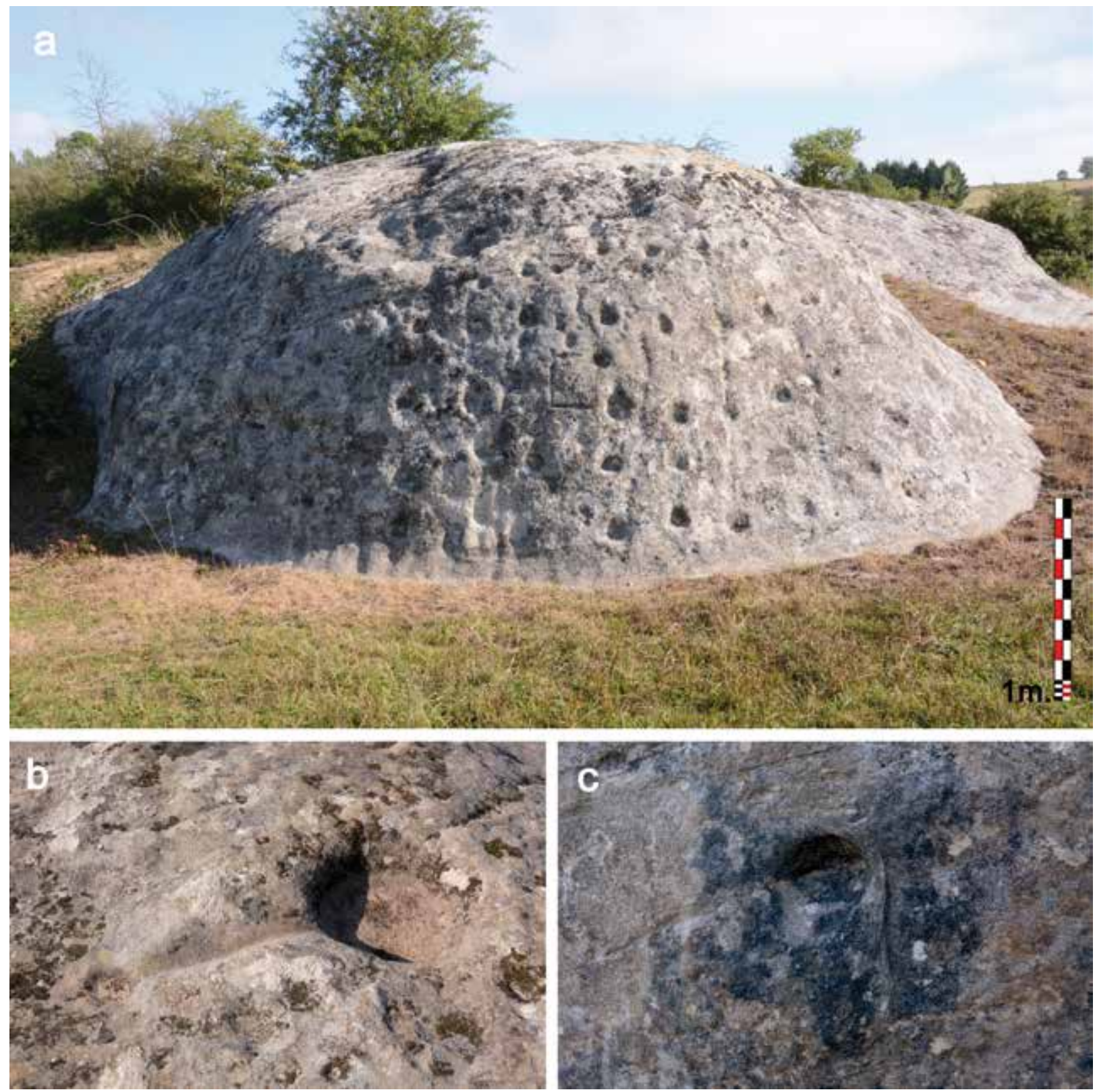

Fig. 4. Altar de Herbosa, en Herbosa-Valle de Valdebezana: a) vista general de la cara sur; b) laciculi de la parte superior; c) detalle de una de las cazoletas de la cara sur. 
Destaca la cara sur de la roca, donde visualizamos cerca de un centenar de cazoletas dispuestas en hileras, muchas de las cuales se encuentran unidas entre sí por pequeños canalillos. Mientras tanto, en la parte superior, sobresalen dos grandes laciculi, receptáculos de unos $40 \mathrm{~cm}$ de diámetro, unidos mediante un canal con sección en forma de $\mathrm{V}$ con otra pequeña cazoleta de $5 \mathrm{~cm}$ de diámetro respectivamente. También en la parte alta de la roca hay más cazoletas de pequeño tamaño y canalillos de menor profundidad, que tienden a desarrollarse hacia la parte más accesible y desgastada de la roca (Fig. 4).

El descubrimiento del lugar fue comunicado por D. Pantano, vecino del municipio.

\subsection{El Castillo I y II, en Alfoz de Santa Gadea}

Ubicado en un gran conjunto rocoso en el que sobresale un gran abrigo
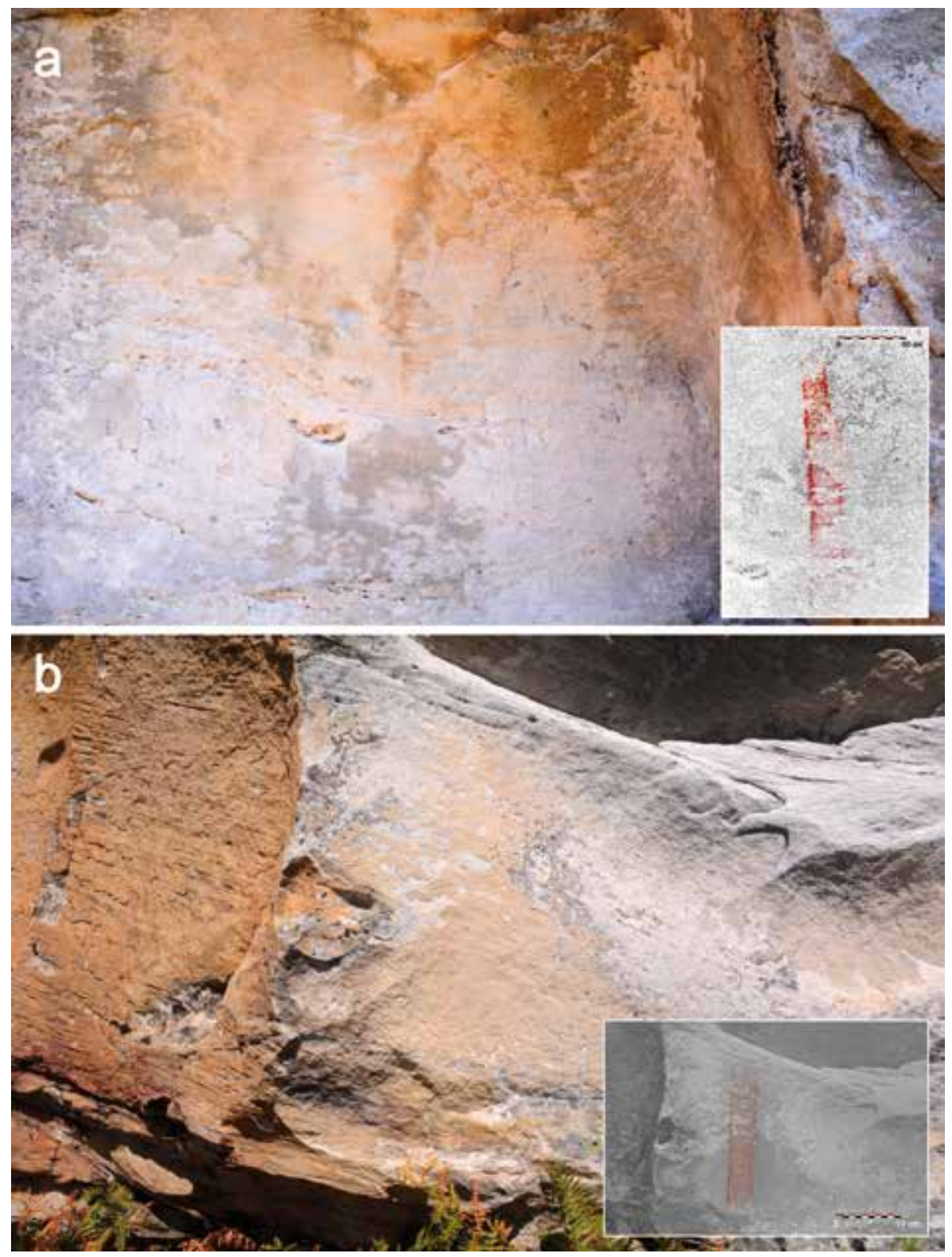

FIG. 5. Escaleriformes en Alfoz de Santa Gadea: a) Castillo I; b) Castillo II.

situado en la parte baja. El lugar se encuentra al pie de la carretera que une Santa Gadea de Alfoz con Los Riconchos, Cantabria. Sobre el citado abrigo se desarrollan amplias paredes lisas en las que se ubican las muestras artísticas, en un avanzado estado de degradación.

En el frente rocoso se localizan dos muestras separadas por varios metros entre sí. En ambos casos nos encontramos con el mismo tipo de figura, dos escaleriformes realizados en pintura roja. El primero de ellos se localiza en la zona central del frente, en una pared plana ligeramente protegida por una pequeña visera. La escalera conserva los dos largueros paralelos, entre los que se disponen al menos once peldaños o escalones. Por su parte, el segundo escaleriforme se localiza en la esquina izquierda del 
citado farallón, de nuevo sobre una pared plana. En este caso la escalera, mejor conservada que la anterior, se compone de los dos largueros paralelos y se pueden apreciar hasta once peldaños o escalones. A su derecha se aprecian restos semiperdidos de pigmento (Fig. 5).

\subsection{Orantes de Santa Gadea I, en Alfoz de Santa Gadea}

Abrigo localizado en la zona central de un gran farallón rocoso, que se desarrolla en dirección SO-NE desde el lugar conocido como Portillo Viejo. En un escalón que hace este frente de roca arenisca se abre un amplio abrigo de aproximadamente $12 \mathrm{~m}$ de largo, $2 \mathrm{~m}$ de fondo y unos $2 \mathrm{~m}$ de altura en su zona central. La boca del mismo se orienta hacia el sur y cuenta con una amplia pared muy lisa separada por una grieta de otra pared superior más estrecha, irregular y peor conservada. Sobre la primera de ellas se disponen las principales muestras artísticas, mientras que en el suelo derecho del abrigo afloran nuevas evidencias.

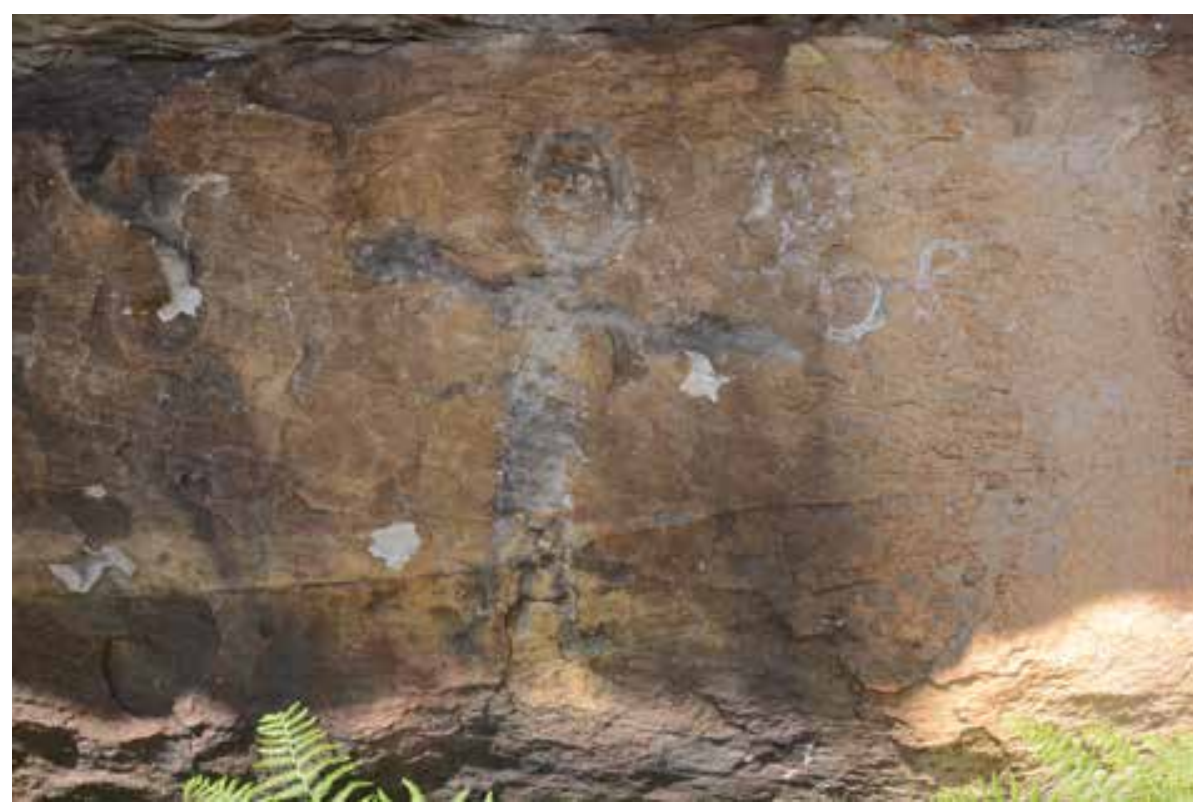

FIG. 6. Antropomorfo en Orantes de Santa Gadea I.
En la parte central del abrigo destaca el grabado de un antropomorfo esquemático con unas dimensiones de $60 \mathrm{~cm}$ de altura $x 50 \mathrm{~cm}$ de anchura. Presenta los brazos abiertos en cruz, cabeza de geometría redonda, con ojos, nariz y boca en su interior, cuerpo con forma alargada de tendencia triangular, piernas ligeramente abiertas rematadas en pies dirigidos hacia afuera y una posible arma entre ambas piernas, teniendo en cuenta la aparición de este tipo de elementos en otras figuras de la zona. La técnica utilizada en su ejecución es la de piqueteado (Fig. 6). En la pared superior, $1 \mathrm{~m}$ a la derecha del antropomorfo, localizamos algunos restos de pigmento rojo diluido, entre los que no es posible adivinar ninguna figuración (Fig. 15b). Por último, en el suelo de la parte derecha podemos observar al menos siete cazoletas unidas entre sí por canalillos de distinto grosor.

\subsection{Orantes de Santa Gadea II, en Alfoz de Santa Gadea}

Se trata de un bloque de roca arenisca de forma ligeramente cúbica que presenta unas medidas de $2 \mathrm{~m}$ de ancho $\mathrm{x} 3,5 \mathrm{~m}$ de lado y unos $2 \mathrm{~m}$ de altura. Se ubica a escasos 10 m del abrigo de los Orantes de Santa Gadea I, delante de su esquina izquierda. El panel se encuentra en la cara S-SE de la roca, la cual está ligeramente inclinada hacia arriba. Esto ha conllevado una mayor erosión y la proliferación de líquenes que dificultan la visión de las figuras.

En el panel localizamos una sola figura grabada. Se trata de un antropomorfo con los brazos doblados hacia 
Postpaleolitico en Las Merindades (Burgos)

arriba en actitud orante, con unas características morfológicas idénticas a las del abrigo anejo. Se repite la cabeza de geometría redonda -con ojos, nariz y boca en el interior-, de la que parten dos líneas oblicuas que se rematan en dos pies abiertos hacia afuera. De esas líneas salen los brazos curvos hacia arriba, en clara actitud orante, los cuales se rematan en grandes manos abiertas. Entre las piernas se diferencia lo que bien podría ser un puñal. Además, del brazo situado a la izquierda cuelga una herramienta alargada, de la cual no es posible diferenciar el tipo de objeto. En este caso la técnica utilizada es un piqueteado, que después se ha visto complementado por un pulido de las líneas (Fig. 7).

\subsection{Orantes de Santa Gadea III, en Alfoz de Santa Gadea}

El lugar está a escasos $30 \mathrm{~m}$ al E de los Orantes de Santa Gadea I y II y junto a uno de los caminos históricos que unían la Meseta con el Cantábrico a través del Monte Hijedo. Se encuentra en una repisa de roca arenisca, orientada al SE, de algo más de $20 \mathrm{~m}$ de largo y $1,5 \mathrm{~m}$ de altura aproximadamente. La repisa se eleva sobre un pequeño abrigo de $18 \mathrm{~m}$ de largo y 1,5 $\mathrm{m}$ de profundidad y unos $2 \mathrm{~m}$ de altura en el punto más elevado. El lugar destaca sobre el entorno, siendo visibles algunas de sus figuras a gran distancia y ejerciendo un buen

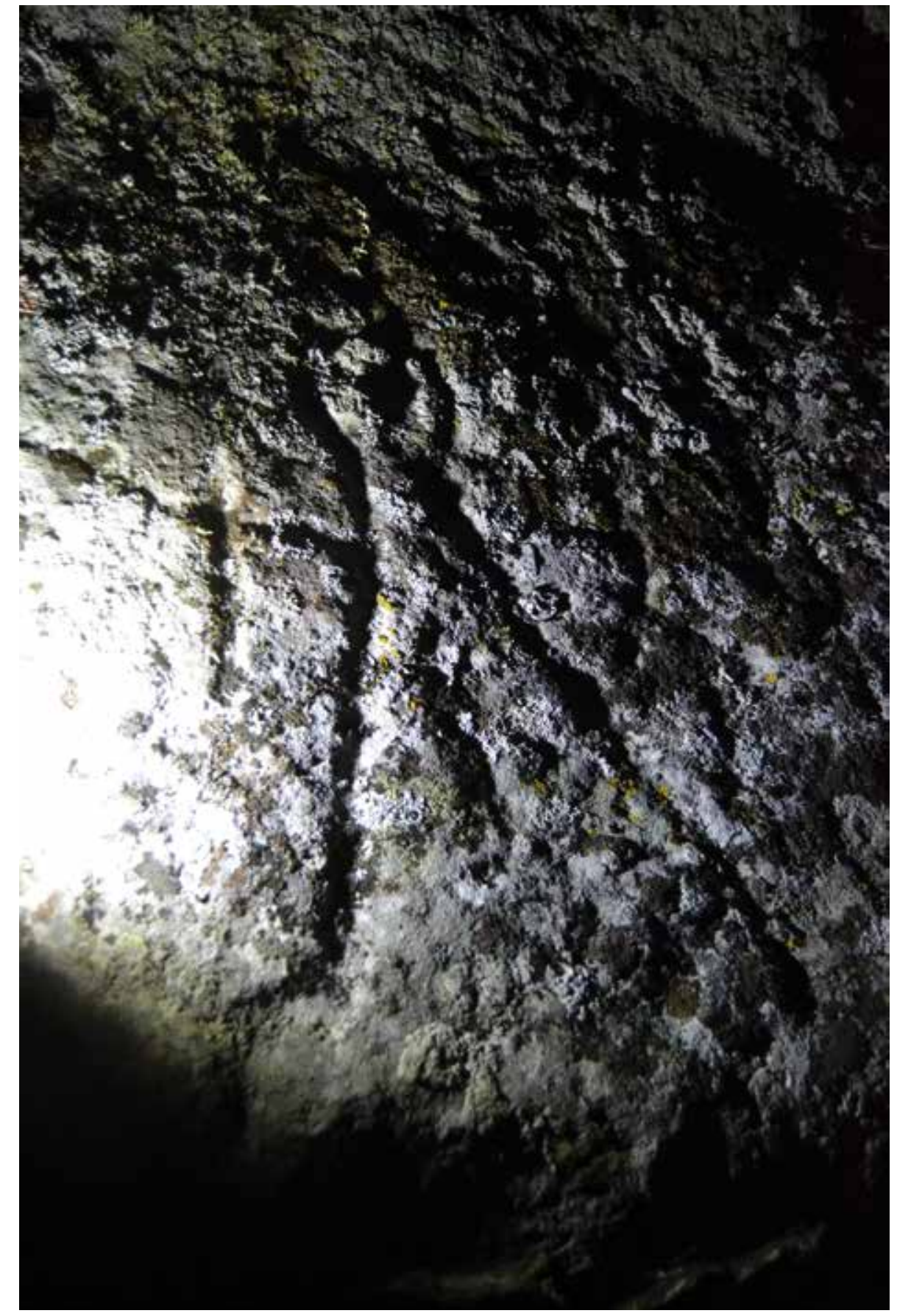

Fig. 7. Orantes de Santa Gadea II. 


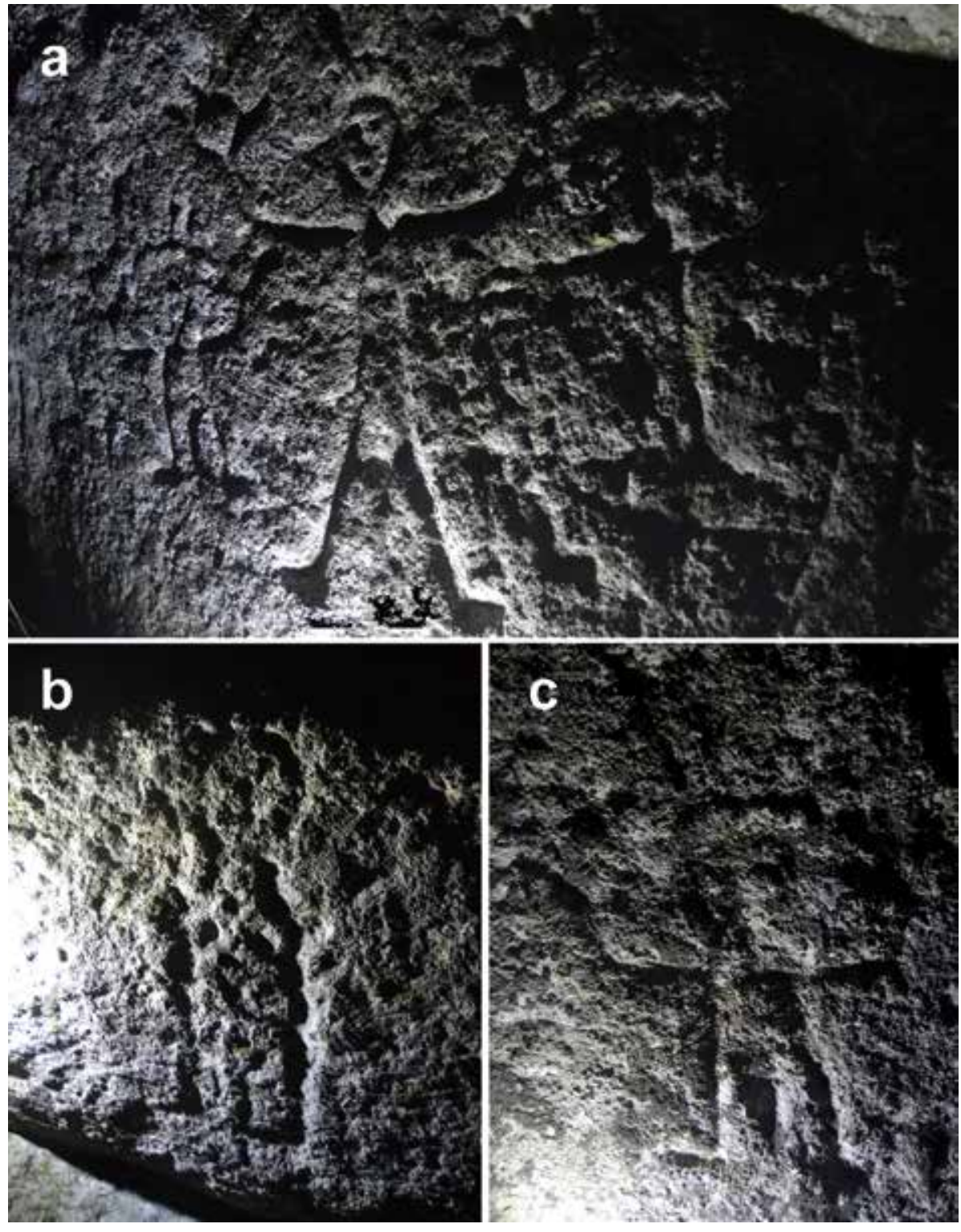

FIG. 8. Orantes de Santa Gadea III: a) panel principal; b) antropomorfo con cuerpo en forma de 'botella de cuello'; c) detalle de puñal entre las piernas.

control sobre toda la llanada de La Virga, el Monte Hijedo y la cabecera del río Ebro o su subsidiario Nela.

En la pared lisa que contiene las grafías podemos reconocer hasta 13 figuras antropomorfas. En primer lugar, cabe destacar los tres antropomorfos de la parte central, puesto que son los más visibles al poseer una técnica más cuidada por la profundidad del trazo (Fig. 8). El antropomorfo central es el más grande de todos ellos, con unas dimensiones de aproximadamente $60 \mathrm{~cm}$ de alto y $50 \mathrm{~cm}$ de ancho. De nuevo se repite la cabeza redonda con ojos, nariz y boca marcadas mediante puntos. Después de un pequeño cuello lineal, arranca un cuerpo de tendencia triangular alargada que acaba desembocando en dos piernas ligeramente abiertas y rematadas con los pies abiertos hacia afuera. De la intersección entre el cuello y el cuerpo, parten dos brazos curvos hacia arriba, en clara actitud orante. Los brazos finalizan en dos grandes manos de cinco dedos, de un tamaño desproporcionado con respecto al resto del cuerpo. La figura porta dos elementos significativos como son un puñal de hoja triangular, al que no es posible diferenciarle el pomo, y un casco adornado con una especie de aletas. A la izquierda de este localizamos un antropomorfo con idénticas características, pero de menor tamaño, y cuya principal diferencia es el casco que corona su cabeza, compuesto por una especie de rayos concéntricos. A la derecha del de mayor tamaño encontramos otro antropomorfo de características similares, pero en este caso dispuesto con una especie de penacho sobre la cabeza. A la izquierda de estos tres observamos al menos otro antropomorfo con este tipo de composición, de menor tamaño y peor conservación. Los 
Postpaleolitico en Las Merindades (Burgos)

nueve antropomorfos que restan se encuentran a la derecha de los citados, a lo largo de varios metros, pero están notablemente afectados por la erosión del soporte. Aun así, podemos diferenciar otro tipo de composición más, en la que la silueta del cuerpo es similar a la de una 'botella de cuello', de la que salen dos piernas, y a cuyo cuello se une una cabeza redonda. En uno de los casos encontramos un antropomorfo cuyo rostro conserva ojos, nariz y boca punteados, mientras que el interior del cuerpo está decorado por una serie de puntos. Otro de los que presentan estas características en forma de 'botella' tiene en el interior del cuerpo un aspa, entre cada uno de cuyos brazos hay un punto. La técnica utilizada es el piqueteado perfeccionado después por un pulido de las líneas, siendo en algunas figuras el trazo más cuidado y profundo.

\subsection{Abrigo de Dujos Altos, en Alfoz de Santa Gadea}

Ascendiendo el valle del arroyo de las Ánimas desde la zona de Portillo Viejo hacia su nacimiento, este se encaja entre grandes paredes de roca arenisca. En una de estas paredes orientada al s encontramos dos abrigos desarrollados en altura, uno encima del otro. El superior cuenta con una explotación apícola tradicional, mientras que debajo de este se abre un abrigo de unos $20 \mathrm{~m}$ de anchura y varios metros de profundidad, el cual destaca por su escasa altura en el interior. Dentro localizamos un friso completamente liso que presenta diversas marcas de pintura roja. En primer lugar, cabe destacar cinco trazos paralelos de diferente altura, siendo los tres centrales más altos y anchos. Se sitúan justo en el borde del friso, en un panel de aproximadamente $10 \mathrm{~cm}$ de anchura y $5 \mathrm{~cm}$ de altura (Fig. 15c). Unos 20 $\mathrm{cm}$ a la izquierda, en el borde de un desconchado

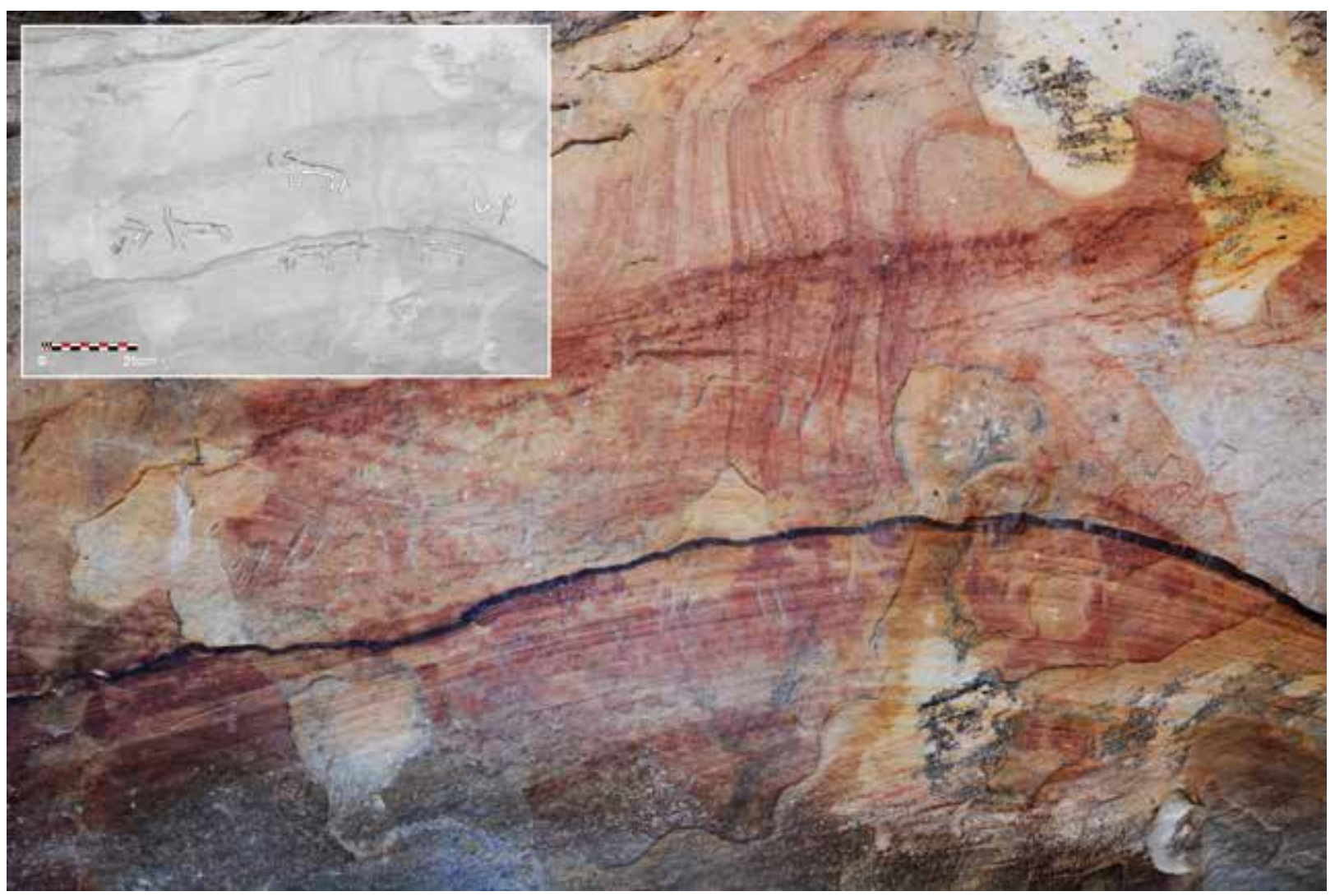

Fig. 9. Peñas Rotas I, en Alfoz de Santa Gadea. 
del soporte, hay una marca de pigmento que indica la presencia de más motivos desaparecidos por la degradación del soporte. Avanzando por el friso, $60 \mathrm{~cm}$ a la izquierda, encontramos dos trazos paralelos que lo cortan por completo en sentido vertical (Fig. 15d). Por último, en el techo inmediatamente anterior al friso podemos localizar dos líneas rojas de distinto tamaño notablemente afectadas por la erosión de la roca. En todos los casos la pintura parece haber sido aplicada mediante el uso directo de los dedos.

\subsection{Peñas Rotas I, en Alfoz de Santa Gadea}

En el topónimo conocido como Peñas Rotas, junto al nacimiento del arroyo de las Ánimas y a escasos $100 \mathrm{~m}$ del parking, y punto de inicio de las rutas de senderismo del Monte Hijedo, se encuentra un abrigo de grandes dimensiones. Cuenta con una boca orientada al oeste de aproximadamente $15 \mathrm{~m}$ de anchura, una profundidad de $3 \mathrm{~m}$ y una altura de unos $4 \mathrm{~m}$. Desde ella hay buen control visual hacia el $\mathrm{N}$ de los grandes farallones que han abierto algunos arroyos que terminan desembocando en la llanada de La Virga. El abrigo se caracteriza por disponer de amplias paredes de tendencia lisa, pero con grandes desconchamientos derivados de la notable erosión a la que está expuesto por su orientación. Será en el tercio izquierdo del abrigo donde se sitúen todas las figuras.

Se trata de un panel con cinco grabados zoomorfos, por cuya fisionomía podríamos identificarlos tal vez como bóvidos o cápridos muy esquematizados. Las figuras que conservan el cuerpo completo presentan unas medidas aproximadas de 25 $\mathrm{cm}$ de largo x $15 \mathrm{~cm}$ de altura. El situado más a la izquierda se encuentra parcialmente perdido por un desconchado, conservando tan solo la parte trasera del animal. Podemos apreciar la línea cérvico-dorsal, que acaba desembocando finalmente en una de las extremidades traseras. De la zona trasera sale una pequeńa línea marcando un rabo corto. Una línea horizontal perfila el vientre, siendo esta interrumpida en cada uno de sus extremos por líneas de

Ediciones Universidad de Salamanca / @ه্త tendencia vertical que conforman la pata delantera y la pata trasera restante. Por debajo de él se encuentran agrupadas una serie de cortas líneas verticales. A su derecha, el siguiente animal es el mejor conservado. Se compone de dos líneas, una externa y otra interna. La externa, comenzando en la extremidad delantera, dibuja el pecho, la cabeza, la línea cérvico-dorsal y culmina en la extremidad trasera. Por su parte la interna, comenzando desde la otra extremidad delantera, dibuja el vientre que termina rematando en la extremidad trasera restante. En este caso podemos diferenciar dos cuernos sobre la cabeza del animal. El animal situado a mayor altura presenta unas características similares a este último, salvo un cuello más prolongado, sin rabo y con las patas delanteras unidas por abajo en sección de U. Bajo él localizamos otro zoomorfo más, en el único caso en el que aparece orientado hacia la derecha. Nuevamente consta de unas líneas externa e interna, pero a diferencia de los anteriores cuenta con un rabo de tendencia apuntada y dibujado con trazos discontinuos. Unido a su cabeza aparece un cruciforme de distinta factura y de época moderna, al igual que la firma pastoril que hay a la derecha del panel. Por último, el situado más a la derecha presenta las mismas características que el segundo, pero está notablemente más erosionado. En todos los zoomorfos la técnica de grabado utilizada es el piqueteado (Fig. 9).

\subsection{Peñas Rotas II, en Alfoz de Santa Gadea}

El lugar se localiza en la esquina exterior izquierda del abrigo de Peńas Rotas I. Se trata de una pared protegida por un pequeño saliente de la roca y, al igual que en el caso anterior, orientada al oeste. Las muestras artísticas se encuentran a apenas $25 \mathrm{~cm}$ del sustrato vegetal.

En la actualidad podemos diferenciar dos zonas en esta pared por su temática. En primer lugar, en la parte superior izquierda, encontramos una figura roja plana desvaída con unas dimensiones de $12 \mathrm{~cm}$ de largo x $10 \mathrm{~cm}$ de alto. Su forma y disposición insinúan los rasgos de una figura zoomorfa, pero el 
estado de conservación no es suficiente como para confirmarlo en rotundidad. Sobre ella, a unos 10 $\mathrm{cm}$, se produce un desconchado del que surge un pequeño trazo que es indicativo de la posibilidad de que hubiese al menos otra figura en esta zona.

En la parte inferior izquierda de la pared, a escasos centímetros del suelo y prácticamente sobre el mismo, podemos apreciar varios motivos. Por un lado, encontramos una serie de puntuaciones conformando lo que se conoce como una nube de puntos. La mayor parte de ellos están realizados con pintura roja diluida probablemente aplicada con digitaciones, mientras que al menos uno de ellos se ha realizado mediante grafitado rojo usando posiblemente un lápiz de ocre. Inmediatamente a la izquierda hay una serie de rayas de tendencia vertical y sin un orden aparente, dibujadas en un tono negro apagado, prácticamente grisáceo, y aplicado probablemente con carbón (Fig. 15e).

\subsection{Peñas Rotas III, en Alfoz de Santa Gadea}

Se ubica en el mismo farallón de roca arenisca en el que se encuentran Peńas Rotas I y II, pero en la vertiente contraria orientada al oeste. Se trata de un amplio abrigo de $25 \mathrm{~m}$ de ancho x $5 \mathrm{~m}$ de profundidad y cerca de $6 \mathrm{~m}$ de altura. El abrigo se caracteriza por disponer de una amplia ventana natural que lo comunica con la vertiente contraria y está notablemente erosionado, tanto por procesos naturales como por la acción humana. Los motivos se distribuyen por varios puntos del abrigo y en una roca desprendida que hay bajo el mismo.

En primer lugar, sobre la gran ventana natural situada en la parte izquierda del abrigo localizamos una serie de rayas de tendencia zigzagueante aplicadas mediante grafitado rojo. Apenas unos centímetros a la derecha encontramos una serie de líneas grabadas con cierta geometría en algunos casos, pero sin figuración aparente. En el lado opuesto del abrigo, en el situado a la derecha, localizamos de nuevo varios restos de pintura roja repartidos por la pared aplicados mediante pintura diluida. Entre estos restos no ha sido posible identificar ninguna

Ediciones Universidad de Salamanca / 요요 figura debido al estado de conservación de las pinturas (Fig. 15f). El último punto en el que podemos identificar representaciones se encuentra en la gran roca que hay en la parte central del abrigo. En su cara superior podemos apreciar un profundo grabado, compuesto de una línea horizontal de $30 \mathrm{~cm}$ de largo y casi $1 \mathrm{~cm}$ en su parte más ancha. La técnica de grabado es el piqueteado.

\subsection{Abrigo del Perro, en Alfoz de Santa Gadea}

Abrigo ubicado en el entorno de la Cernolica, bajo el camino forestal que lleva a la Cabaña del Hijedo. Cuenta con unas dimensiones de $15 \mathrm{~m}$ de anchura y $5 \mathrm{~m}$ de fondo, mientras que su altura va de los 2,3 $\mathrm{m}$ de la boca hasta los apenas $30 \mathrm{~cm}$ del fondo. Se orienta al SE, teniendo un excelente control visual sobre la cabecera del arroyo del Hijedo, el Monte Hijedo, las peñas de la Cernolica y, por supuesto, sobre las cercanas estaciones con arte de Jinetes de la Cernolica, Corral del Barrio Abajo y Peñas de la Cernolica. En el interior del abrigo hay una pared plana a modo de friso, de unos $90 \mathrm{~cm}$ de anchura, que discurre de manera continua a lo largo del mismo. Será sobre el cantil de este friso donde se desarrollen las grafías.

Toda la pintura roja se encuentra en un panel de unos $70 \mathrm{~cm}$ de largo y $60 \mathrm{~cm}$ de altura, y a tan solo $90 \mathrm{~cm}$ del suelo del abrigo. En la esquina inferior del panel podemos diferenciar una figura antropomorfa esquemática. Una ancha línea vertical de 3,5 $\mathrm{cm}$ de grosor esboza el cuerpo, del que arrancan dos brazos a media altura y las piernas en la parte de abajo, en ambos casos en forma de arco. Sobre la cabeza podemos ver que la figura porta un casco o tocado de forma ligeramente curvada y que sobresale por ambos lados. El antropomorfo aparece acompańado por encima a su izquierda de al menos tres grupos de líneas subparalelas de tendencia vertical, que en el caso del grupo situado a la izquierda supera los $30 \mathrm{~cm}$ de largo. Aún más a la izquierda encontramos una gran mancha roja en la que no es posible adivinar figura alguna. Finalmente a la derecha del panel, tras una grieta vertical 


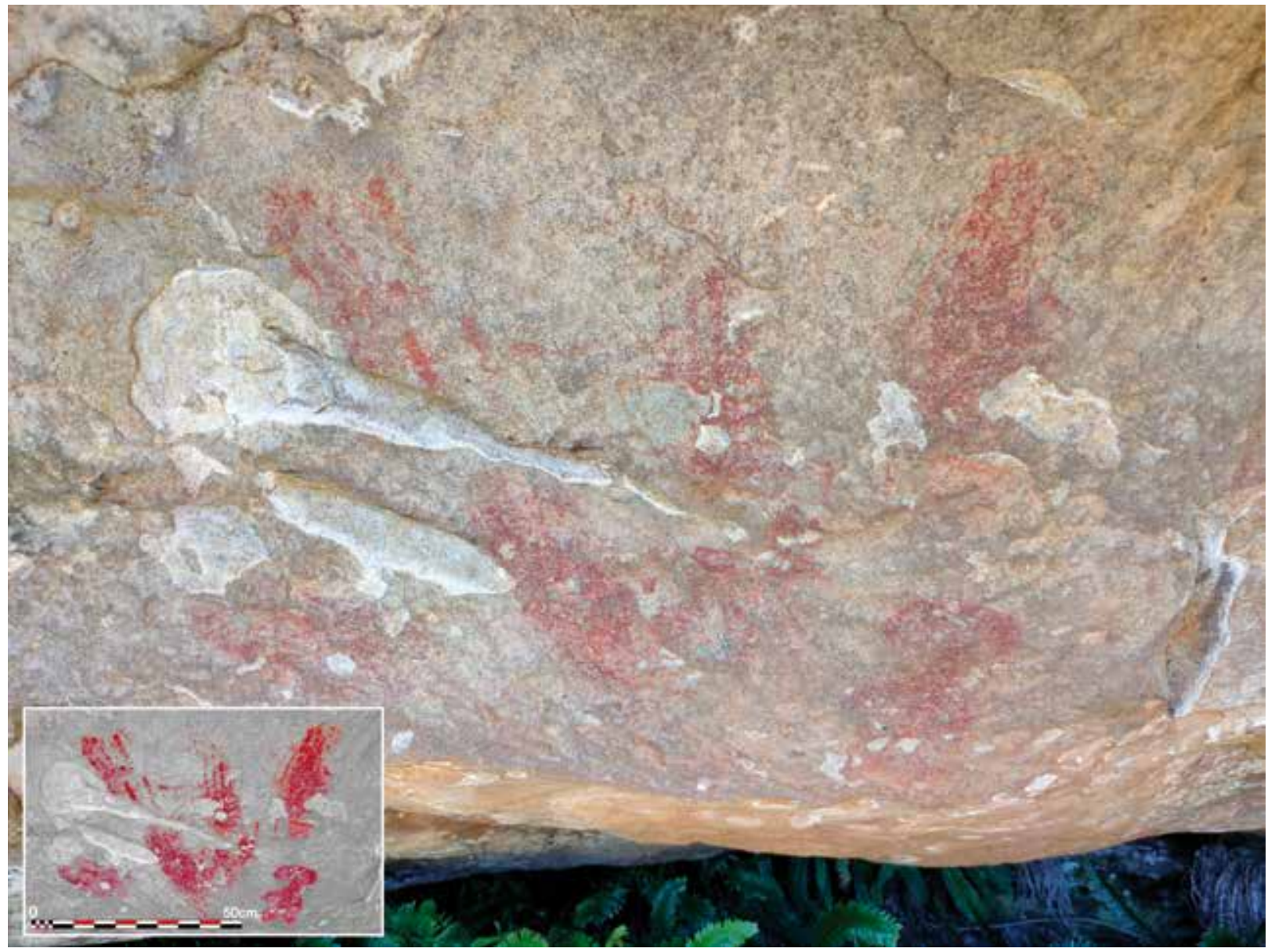

Fig. 10. Abrigo del Perro, en Alfoz de Santa Gadea.

del friso, hay una pequeña marca de pintura. En todos los casos la técnica utilizada sería la pintura roja diluida y probablemente aplicada mediante digitaciones (Fig. 10).

\subsection{Jinetes de la Cernolica, en Alfoz de Santa Gadea}

Estación localizada en el paraje conocido como la Cernolica, un entorno que se caracteriza por albergar altos farallones de roca arenisca que se desarrollan de manera continua de o a E. La pared en la que se encuentran las representaciones está orientada al sureste y se ubica en una zona ligeramente elevada, al pie de un entrante que se forma en el propio farallón. Bajo este lugar se contempla el nacimiento del arroyo del Hijedo, sobre el que ejerce un completo control visual de su cabecera. Además, en un radio de apenas 300 m encontramos al menos otros tres lugares con pinturas, como es el caso de Corral del Barrio Abajo, Peñas de la Cernolica o el abrigo del Perro. El soporte donde se ubican las pinturas se encuentra protegido por una visera, conformando un pequeño cubículo con diversas hornacinas de paredes abombadas delimitadas por suaves aristas.

En el cubículo las figuras más destacadas se ubican en la parte central y están compuestas por un grupo de tres jinetes que ascienden por una de las aristas, incluyendo intencionalmente el relieve del soporte como parte de la escena. El jinete situado a 
la izquierda no conserva definida la cabeza del caballo, que se encuentra completamente desvaída. Los caballos están compuestos por trazos simples que conforman orejas, cuello, línea cérvico-dorsal, rabo, nalgas y vientre. Del cuerpo parten hacia abajo las extremidades delanteras y traseras, de nuevo con trazos muy simples, rematadas en algunos casos en pezuñas triangulares. De la cabeza del caballo parten las riendas que se unen con el jinete. Centrándonos en la figura de los jinetes, estos constan de un cuerpo muy esquemático compuesto por una línea vertical conformando el cuerpo y dos brazos y piernas que salen de esa línea corporal. La parte superior del cuerpo se corona con una cabeza redonda, sobre la que podemos apreciar un casco de forma picuda. Sobre ellos, en la esquina izquierda, se localiza otro jinete de similares características, pero de mayor tamaño y más desvaído en la parte inferior del animal. Pese a ello, podemos diferenciar sus patas delanteras, siendo la pezuña de una de ellas bastante detallada en comparación con las del resto de caballos. En la pared derecha del abrigo se repite el mismo motivo, apareciendo en este caso dos jinetes superpuestos. Todos los jinetes y sus caballos tienen dibujado su contorno mediante grafitado rojo, mientras que el interior se ha realizado mediante pintura roja diluida (Fig. 11).

En la esquina derecha de la pared principal localizamos de nuevo dos caballos, pero, a diferencia de los anteriores, de composición distinta y sin jinetes sobre sus lomos. Los caballos disponen de una cabeza apuntada hacia abajo, dos orejas picudas, un cuerpo alargado y el rabo prolongado en línea recta hacía atrás. Por la parte baja del animal sobresalen las extremidades. En el caso del caballo superior las extremidades indican acción de galope, puesto que se encuentran plegadas. Por el contrario, en el caso del caballo inferior las extremidades son alargadas

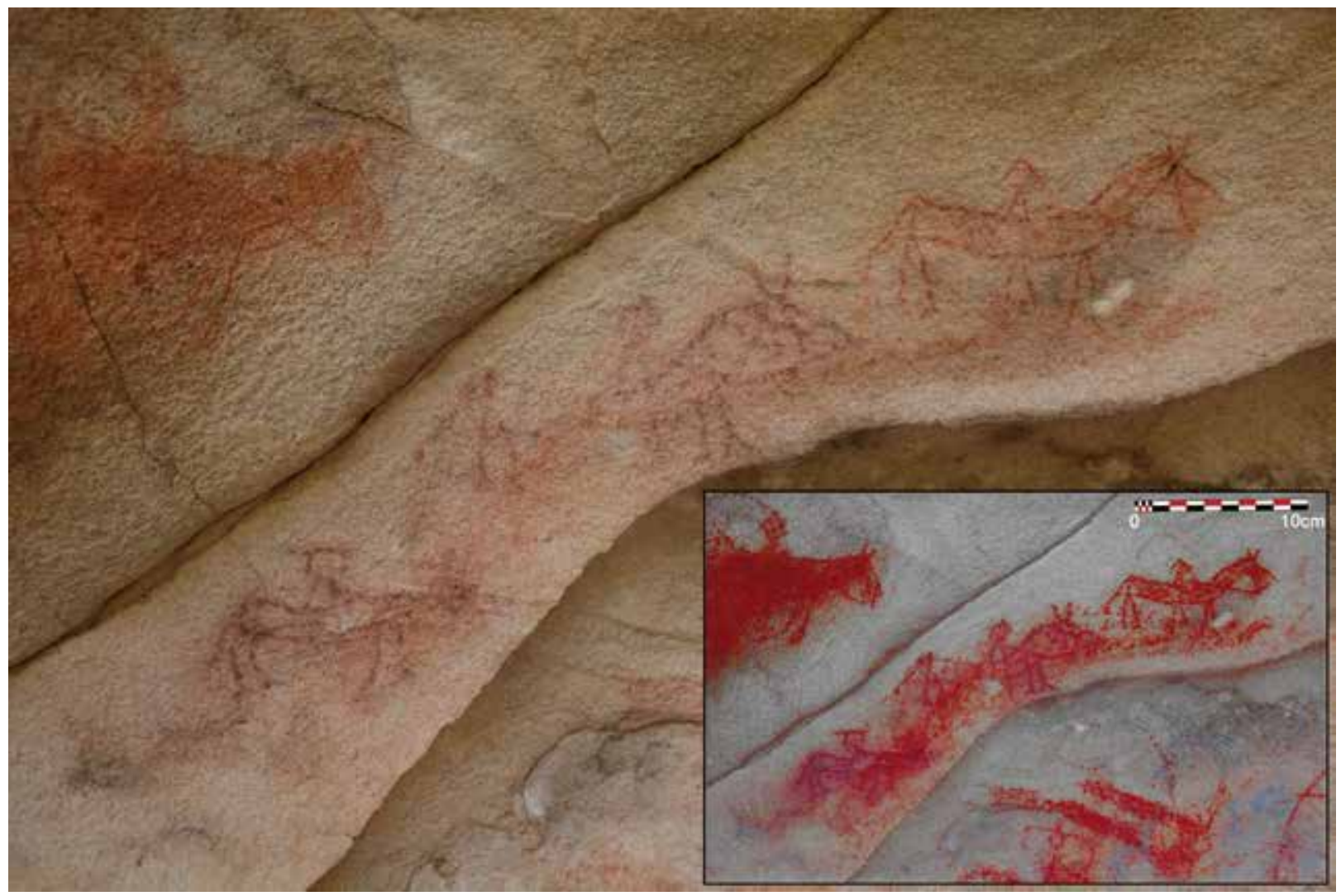

Fig. 11. Grupo de jinetes en el panel principal de Jinetes de la Cernolica, en Alfoz de Santa Gadea. 
y se rematan en pezuñas punteadas. Junto con ellos observamos una serie de rayones en rojo entre los que no existe figuración alguna.

En la hornacina más grande encontramos una figura en color negro que destaca sobre el resto. Se trata de un cuadrúpedo esquemático orientado hacia la derecha. Tiene bien diferenciado su tronco alargado en disposición horizontal, el cual se prolonga hacia la izquierda rematándose en una cola ligeramente curvada hacia abajo. Por la parte inferior vemos las patas en disposición vertical, dispuestas dos a dos, siendo las delanteras más prolongadas que las traseras. De la intersección entre una de las extremidades traseras y la línea del cuerpo parte otra línea transversal que bien podría ser el falo del animal. En la zona delantera del mismo surgen una serie de trazos hacia arriba que parecen conformar los cuernos de un cérvido (Fig. 12). Encontramos otra serie de rayas negras repartidas en el frente del abrigo infrapuestas claramente a las pinturas rojas que hay sobre ellas. Superpuesta a todas, y de claro aspecto moderno, encontramos en pintura negra la silueta de una cara humana. Finalmente, debemos señalar la presencia de una pequeña cazoleta, a modo de semiesfera, localizada en el suelo inmediato al cubículo donde se encuentran las pinturas.

En 2010, la existencia de esta estación rupestre fue comunicada por el Grupo de Arqueología 'Antxieta' al Servicio Territorial de Arqueología de la Junta de Castilla y León en Burgos y se presenta en esta obra de manera inédita.

\subsection{Corral del Barrio Abajo, en Alfoz de Santa Gadea}

Se trata de un gran afloramiento aislado de roca arenisca de $50 \mathrm{~m}$ de largo y $15 \mathrm{~m}$ de altura.

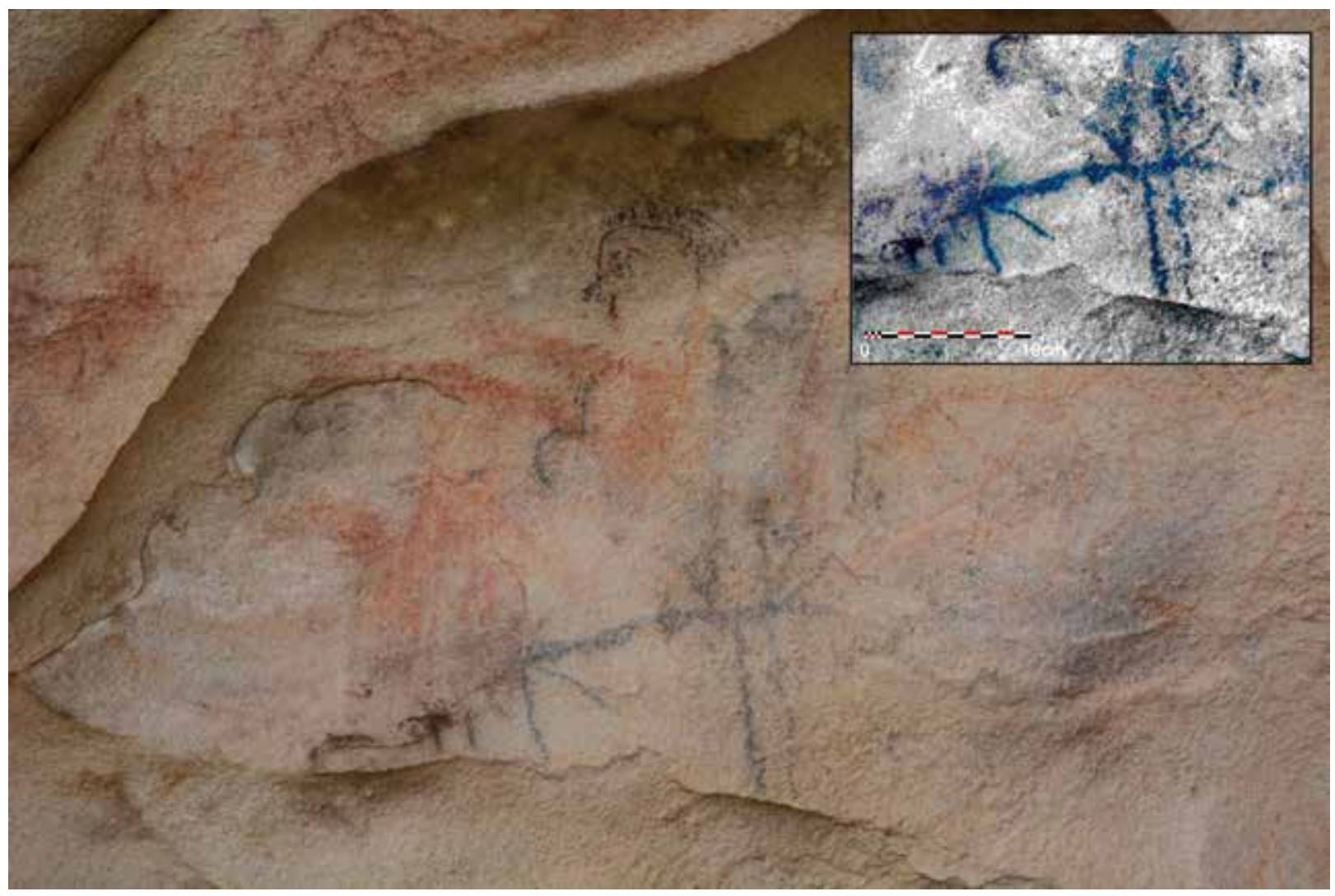

FIG. 12. Cuadrúpedo esquemático negro en Jinetes de la Cernolica, en Alfoz de Santa Gadea. 




Fig. 13. Corral del Barrio Abajo, en Alfoz de Santa Gadea.

Se localiza a apenas $100 \mathrm{~m}$ al s de los grandes farallones que componen la Cernolica. En su parte baja se genera una especie de abrigo protegido por una visera natural y con sus paredes orientadas al sur.

Este lugar fue dado a conocer por Teira y Ontañón (1997: 573) junto con otros lugares del entorno como Peńas de la Cernolica. En la pared protegida por la visera, a 1,8 $\mathrm{m}$ de altura, localizaron una figura ancoriforme rematada en la zona superior con varios puntos a modo de tamponado que conforman una figura triangular. Tras la revisión del lugar hemos localizado inmediatamente encima del ancoriforme un trazo transversal de unos $9 \mathrm{~cm}$. A su izquierda observamos un pectiniforme compuesto por un trazo horizontal de $15,5 \mathrm{~cm}$ del que parten varias líneas paralelas hacia abajo, de unos $7 \mathrm{~cm}$ cada una de ellas, figura que bien podría suponer la esquematización de un cuadrúpedo. Algo más arriba del pectiniforme surge una figura antropomorfa que conserva el trazo vertical que compone el cuerpo, de $9,7 \mathrm{~cm}$ de altura, y el brazo y la pierna izquierda dispuestos en ambos casos de forma curva hacia abajo. Aún más a la izquierda encontramos un tectiforme ovalado dividido hacia la mitad por una línea horizontal y en cuyo interior apreciamos al menos dos líneas oblicuas que se unen perpendicularmente al trazo horizontal. Unos centímetros a la izquierda observamos dos líneas subparalelas de $13 \mathrm{~cm}$ y 10 $\mathrm{cm}$ respectivamente. Por último, $25 \mathrm{~cm}$ debajo del antropomorfo, aparece aislado un punto (Fig. 13).

\subsection{Orantes de La Zapata, en Montejo de Bricia- Alfoz de Bricia}

El lugar se localiza en una zona denominada 'Los Portillones', que se caracteriza por la presencia de un largo farallón de roca arenisca desarrollado de 
forma continua de $\mathrm{O}$ a $\mathrm{E}$, en el que abundan grandes paredes y abrigos. Los Orantes de La Zapata se localizan en una gran roca individualizada del farallón y ubicada en el nacimiento del arroyo homónimo. La parte baja de esta gran pared, de aproximadamente $6 \mathrm{~m}$ de altura, dispone de un panel muy liso orientado al sureste en un perfecto estado de conservación, siendo este el lugar donde se disponen las grafías prehistóricas junto a grabados modernos.

Se trata de dos figuras antropomorfas de cuerpo circular, de las cuales tan solo dispone de cabeza, también en forma de círculo, la situada a la izquierda. En ambos casos del cuerpo arrancan dos brazos simples orientados hacia arriba, en clara actitud orante, mientras que las extremidades inferiores se representan mediante dos trazos verticales y paralelos entre sí. Las piernas están rematadas por pies punteados en el caso del antropomorfo derecho, mientras que en el caso del izquierdo sus pies aparecen orientados hacia afuera. Pero quizás lo más destacado de la composición es que el antropomorfo izquierdo se sitúa en el interior de un arco de medio punto. La técnica de grabado empleada es el piqueteado, pudiéndose haber combinado con el pulido de las líneas en el antropomorfo izquierdo y en el arco que lo corona (Fig. 14).

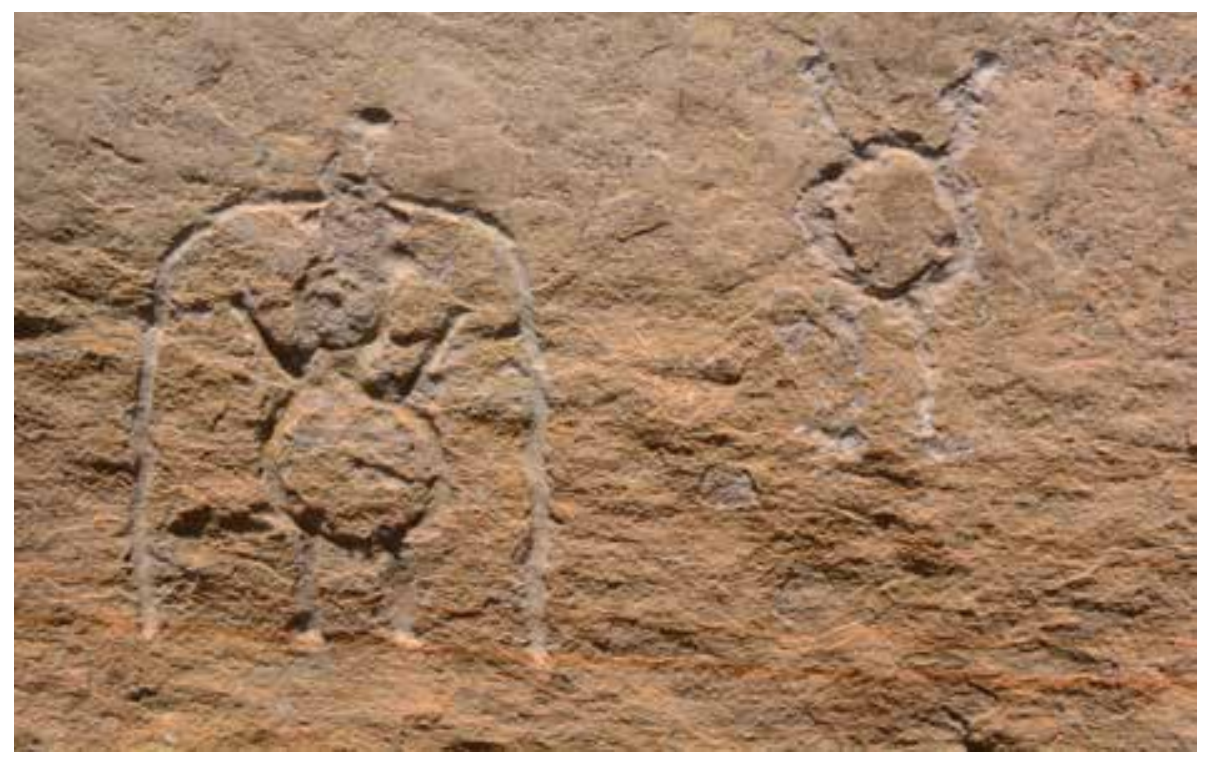

Fig. 14. Orantes de La Zapata, en Montejo de Bricia-Alfoz de Bricia.

\section{Discusión: la difícil atribución cronológica del Arte Postpaleolítico}

No cabe duda de la importancia que tiene para la investigación arqueológica el hecho de poder dotar de una periodización al arte rupestre. En el caso del Arte Rupestre Paleolítico la tradición investigadora continuada ha supuesto que en la actualidad podamos consensuar una serie de periodos ampliamente aceptados por la comunidad científica. La presencia de arte mueble en paralelo exhumado en posición estratigráfica, la aplicación de técnicas radiométricas directas -C14-AMs- o indirectas - $\mathrm{U} / \mathrm{TH}$, TL-, la amplitud del corpus o el propio hecho de que las cuevas se configuren en ocasiones como unidades cerradas de estudio favorecen cierta concreción en este sentido. Sin embargo, cuando nos referimos al Arte Rupestre Postpaleolítico los elementos que nos ofrecen información de carácter cronológico son mucho más escasos, siendo en ocasiones prácticamente nulos. De hecho, el propio término de Arte Rupestre 'Postpaleolítico' carece de una definición clara y precisa. Así, podemos consultar publicaciones que incluyen dentro de ese término todo aquel arte no paleolítico (Serna et al., 2016: 10-11); es decir, un amplio marco cronológico que comprende todo el Holoceno hasta la actualidad. En otros casos, acotan el término 'postpaleolítico' tan solo para arte de momentos prehistóricos posteriores al Paleolítico, llegando en unos casos hasta la Edad del Bronce (Beltrán, 1989: 97-111; 1993: 187-201) y ampliándolo en otros hasta el cambio de Era (Royo, 2009: 38). Estos últimos, además, emplean en ocasiones el término 'arte prehistórico’ para estas cronologías, lo que ańade mayor confusión. Aun aceptando 
alguna de estas propuestas, es necesario establecer fases internas que permitan una mejor comprensión. Pero esto es algo que el estado incipiente en el que se encuentran las investigaciones, al menos en el caso de la Cordillera Cantábrica en general, y del Alto Ebro en particular, impide realizar. Ello se debe a la escasez de dataciones directas y de contextos arqueológicos que se puedan relacionar con las representaciones artísticas de estas cronologías, especialmente en yacimientos al aire libre.

Todo ello conlleva que en la actualidad solo sea posible establecer una cronología poco precisa de cada una de las estaciones que hemos presentado, basada principalmente en una comparación formal con otros lugares de similares características, así como en la secuencia estratigráfica parietal de aquellos casos que disponen de superposición entre figuras. En el caso de este artículo, se ha decidido incluir dentro del Arte Postpaleolítico del N de Burgos a aquellos lugares con una posible atribución cronológica posterior al Paleolítico, poniendo el cambio de era como límite cronológico. Pese a que los paralelos existentes permiten proponer una determinada cronología, la ausencia de dataciones directas o de estudios del contexto arqueológico impiden descartar por completo la posibilidad de que algunas grafías pertenezcan a épocas posteriores.

A continuación, exponemos una hipótesis de la posible atribución cronológica de estos nuevos hallazgos, haciendo en primer lugar una relación de aquellas estaciones con escasa definición por la sencillez de la muestra. Tras ello, seguiremos un orden cronológico desde las más antiguas a las más modernas, sin atender a la técnica empleada, tratando por último la estación de Jinetes de la Cernolica por contar con diversas etapas de utilización.

Así, los paralelos existentes en la zona atribuidos por otros autores a la Prehistoria Reciente, nos llevan a pensar en cronologías similares para lugares con pintura roja diluida, como la nube de puntos de Peñas Rotas II, los restos de pintura de Peñas Rotas III y Orantes de Santa Gadea I, los conjuntos de trazos de los abrigos de Bustasabina y Dujos Altos, los escaleriformes del Castillo i y in o las figuras de Corral del Barrio Abajo. La simplicidad de todas

Ediciones Universidad de Salamanca / 요 estas muestras y su pobre estado de conservación nos impiden acotar más el periodo cronológico al que pertenecen. Algo similar ocurre con los Orantes de La Zapata, en este caso grabados, los cuales comparten características con el subtipo 1 que establece L. Baltzer (1881) para los petroglifos de la región del Bohuslän, Suecia, y que Sobrino (1956) compara con petroglifos antropomorfos de Galicia. Ambos casos son asignados a la Prehistoria Reciente, por lo que podría ser factible una atribución similar para La Zapata.

En otros casos es posible acotar las fechas dado que nos encontramos con paralelos mejor estudiados, como es el caso del abrigo del Perro. Su antropomorfo es asimilable al tipo A4.1 propuesto por Gómez Barrera (1991) y a las pinturas existentes en la Cueva de los Hornillos, Cejancas, Cantabria (Martínez Velasco, 2016: 335); la Cueva de El Castillo (Alcalde del Río et al., 1911: 193; Breuil, 1933: 37-42), o al antropomorfo que decora un fragmento cerámico hallado en el Portalón de Cueva Mayor de Atapuerca, Burgos (Alday et al., 2017: 125-137). El contexto arqueológico en el caso de la Cueva de El Castillo indicó unas fechas situadas entre el Calcolítico avanzado y el Bronce Pleno (Teira y Ontañón, 2016b: 246), mientras que el fragmento cerámico localizado en el yacimiento del Portalón ha sido atribuido a época neolítica (Alday et al., 2017: 125137). Por ello, es posible que las pinturas del abrigo del Perro se encuadren en esos momentos situados entre el Neolítico y la Edad del Bronce.

Un lugar que podemos atribuir a la Edad del Bronce es el de Peñas Rotas I, cuyos grabados zoomorfos comparten características estilísticas con algunos petroglifos gallegos, como los de Pedra Boullosa o Pedra das Ferraduras, en Campo Lameiro, Pontevedra, para los que se aceptan generalmente cronologías entre el III milenio a. C. y el II milenio a. C., no siendo descartable la continuidad de este tipo de representaciones durante la Edad del Hierro (Fábregas y Rodríguez-Rellán, 2012: 249-259).

Los paralelos encontrados con otros grabados permiten situar algunas estaciones en momentos comprendidos entre la Edad del Bronce y la Edad del Hierro. Este es el caso de los Orantes de Santa 



Fig. 15. Pinturas rojas: a) Abrigo de Bustasabina, en Ahedo de las Pueblas-Merindad de Valdeporres; b) Orantes de Santa Gadea I, en Alfoz de Santa Gadea; c-d) Abrigo de Dujos Altos, en Alfoz de Santa Gadea; e) Peñas Rotas II, en Alfoz de Santa Gadea; f) Peñas Rotas III.

Gadea, cuyos antropomorfos de manos y piernas abiertas presentan similitudes con los encontrados en lugares como Castro Colorado, León; el Cero de San Isidro, en Domingo García, Segovia; los grabados de la sierra de Guadarrama, Madrid; o Mas N’Olives, Lérida (Royo y Campos, 2015:
153; De Balbín y Moure, 1988; Royo, 2004: 59; Royo, 2009: 45), mientras que los de cuerpo en forma de 'botella' encuentran un paralelo directo en el cercano abrigo de la Calderona, en Olleros de Paredes Rubias, Palencia (Rincón, 1993). Lo mismo ocurre en el caso del Altar de Herbosa, en 
el que la abundancia de cazoletas y la presencia de laciculi con canalillos hacen que lo pongamos en relación con las conocidas como 'peñas sacras' o $s a$ cra saxa, que son más numerosas en lugares del no de la Península (Almagro-Gorbea, 2015: 329-410). El ejemplo más cercano estudiado lo podemos encontrar en las 'Peñas Sacras' de Gete (Pinilla de los Barruecos, Burgos) (Almagro-Gorbea et al., 2018: 217-240). Por lo general, estos lugares se atribuyen a cronologías que oscilan entre el Bronce final y el Hierro II.

Pero quizás, desde el punto de vista cronológico, el lugar que ofrece una mayor complejidad de interpretación es el de Jinetes de la Cernolica. Ello se debe a la reutilización del lugar que hemos podido identificar en, al menos, cuatro momentos, siendo los dos últimos claramente en un periodo moderno. Sin embargo, los otros dos momentos pertenecerían muy probablemente a fechas prehistóricas. La figura más antigua que hemos podido identificar es el zoomorfo esquemático pintado en color negro, dado que está infrapuesto al resto de pinturas. Este se puede asimilar al Tipo в3 propuesto por Gómez Barrera (1991) o a la estructura iconográfica Esso 12 propuesta por Mas Cornellá (2001), siendo esta una figura frecuente en el Arte Esquemático de la Península, y de la que podemos encontrar paralelos cercanos en dos figuras de la Cueva de los Hornillos (Martínez Velasco, 2016: 333-342) y en los grabados de cérvidos esquemáticos de Cueva de Kaite y la Sala de la Fuente, ambas situadas en Ojo Guareña (Ortega y Martín Merino, 2013: 169-174; $207-$ 213). Su infraposición a las pinturas rojas, así como la atribución cultural de los paralelos señalados, hacen posibles cronologías situadas entre el Neolítico y el Calcolítico. Por su parte, los jinetes realizados en color rojo se asemejan al grabado ecuestre de Tipo c3.5 propuesto por Royo (2005: 157-200), y las figuras de jinetes del abrigo 9 del Barranco de la Mata, en Sotillos de Caracena, Soria, o el abrigo $\mathrm{x}$ del Cingle de Mola Remigia, en Ares de Maestre, Castellón (Gómez-Barrera, 1992: 160; Royo, 2005:

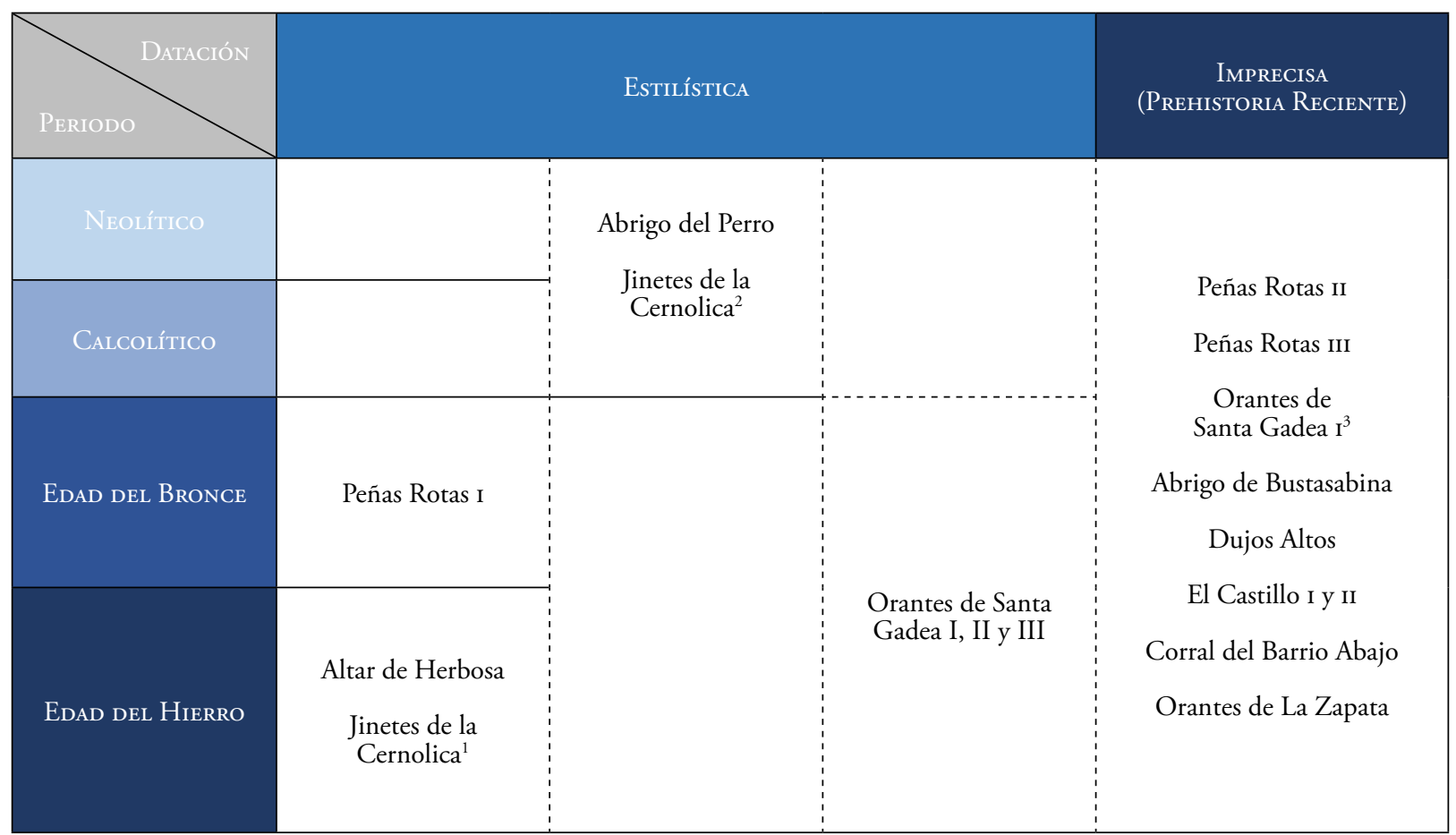

Fig. 16. Propuesta de atribución cronológica de las nuevas evidencias (1. Jinetes y resto de trazos rojos superpuestos; 2. Zoomorfo y pinturas negras infrapuestas; 3. Restos de pintura roja). 
171-172), dichos paralelos podrían situarlos en los momentos finales de la Prehistoria, durante la Edad del Hierro.

Pese a los indicios de una cronología prehistórica postpaleolítica para estos lugares, quedan palpables las dificultades encontradas para poder establecer una cronología definitiva que vaya más allá de meras hipótesis sustentadas en comparativas. Esto es algo que solo podrá solucionarse con el estudio futuro de los posibles contextos arqueológicos que puedan ponerse en relación con las muestras artísticas.

\section{Conclusiones}

Gracias a los trabajos de prospección desarrollados en el No de Burgos, se pudieron localizar un total de 14 nuevas estaciones, así como una serie de nuevas figuras en lugares ya conocidos. Esto ha elevado el número de ubicaciones con Arte Rupestre Postpaleolítico en la zona a un total de 19, lo que supone un aumento de un $280 \%$ sobre lo ya conocido en el área de estudio y ha permitido completar el vacío que existía en la zona en comparación con las áreas limítrofes señaladas. Este aumento notable del registro arqueológico convierte al Alto Ebro en un destacado foco de arte de estas cronologías y permitirá un conocimiento mucho más profundo del fenómeno gráfico rupestre postpaleolítico no solo en esta zona en particular, sino en toda la Cordillera Cantábrica.

\section{Bibliografía}

Alcalde del Río, H.; Breuil, H. y Sierra, L. (1911): Les cavernes de la Région Cantabrique. Mónaco: Imprenta V. Chène.

Alday, A.; Iriarte, E.; Pérez-Romero, A. y FranCÉs-Negro, M. (2017): "Pottery with ramiform-anthropomorphic decoration from El Portalón de Cueva Mayor site (Sierra de Atapuerca, Burgos) and the globalized symbolic world of the first Neolithic", Quaternary International, pp. 125-137.

Almagro-Gorbea, M. (2015): "Sacra Saxa. 'Peñas Sacras' propiciatorias y de adivinación de la Hispania céltica", Estudios Arqueológicos de Oeiras, 22, pp. 329410.

Almagro-Gorbea, M.; Ruiz, I. y Palacios, M. V. (2018): "Las 'Peñas Sacras' de Gete (Pinilla de los Barruecos, Burgos): sobre religiosidad celta en el Alto Valle del Río Arlanza", Arqueología en el valle del Duero. Del Paleolítico a la Edad Media, 6, pp. 217240.

BAltzer, L. (1881): Glyohes des rochers du Bohuslän. Gothembourg, 2 vols.

Beltrán, A. (1989): "Digresiones sobre el arte esquemático de aspecto prehistórico y sus versiones medievales y modernas: problemas de método". En Aragón en la Edad Media, VIII. Homenaje al profesor emérito A. Ubieto Arteta. Zaragoza, pp. 97-111.

Beltrán, A. (1993): Arte Prehistórico en Aragón. Zaragoza: IberCaja.

Bohigas, R.; Campillo, J. y Churruca, J. A. (1984): "Carta arqueológica de la provincia de Burgos. Partidos judiciales de Sedano y Villarcayo", Kobie, xIv, pp. 7-91.

Breuil, H. (1933): Les peintures rupestres schématiques de la Péninsule Ibérique. Polignac: Fondation Singer.

Bueno, P. (1982): "La estela antropomorfa del collado de Sejos (Valle de Polaciones, Santander)", Trabajos de Prehistoria, 39, pp. 342-348.

Carballo, J. (1921): "El Neolítico en el Norte de España", Boletín de la Real Sociedad Española de Historia Natural, xxI, pp. 348-350.

Carballo, J. (1936): Los grabados prehistóricos de Cabrojo. La Coruńa: Ayto. de Cabezón de la Sal.

De Balbín Behrmann, R. (1989): "El arte megalítico y esquemático del Cantábrico". En González, M. R.: Cien años después de Sautuola. Santander: Gob. de Cantabria, pp. 15-96.

De Balbín Behrmann, R.; González Morales, M. R.; Serna, M. R. y González Sainz, C. (1983): "Informe sobre el conjunto de grabados rupestres al aire libre de la Braña de los Pastores", Zephyrus, xxxvı, pp. 93-104.

De Balbín Behrmann, R. y Moure, J. A. (1988): "El arte rupestre de Domingo García (Segovia)", Revista de Arqueologia, 87, pp. 16-24.

Díaz CASAdo, Y. (1993): El arte rupestre esquemático en Cantabria. Santander: Univ. de Cantabria.

Ebert, D. (2004): Predictive modeling and the Ecology of Hunter-Gatherers of the Boreal Forest of Manitoba. BAR Intern. Ser., 1221. Oxford: Archaeopress.

FÁbregas, R. y Rodríguez-Rellán, C. (2012): "Images in their Time: New Insights into the Galician 
Petroglyphs”. En Jones, A. M.; Pollard, J.; Allen, M. J. y Gardiner, J. (eds.): Image, Memory and Monumentality. Archaeological engagements with the material world: a celebration of the academic achievements of Professor R. Bradley. Prehistoric Society Research, 5. Oxford: Oxbow Books, pp. 249-259.

Fraile, M. A. (2004): Catálogo de castros cántabros. Santander.

García SANJuÁn, L. (2004): "La prospección arqueológica de superficie y los Sig". En Martín de la Cruz, J. C. y Lucena, A. M. (eds.): Informática aplicada a la investigación y la gestión arqueológicas. Actas I Encuentro Internacional (Córdoba, 2003). Córdoba: Univ. de Córdoba, pp. 185-210.

Gómez-Barrera, J. A. (1991): "Contribución al estudio de los grabados rupestres postpaleolíticos de la Península Ibérica: las manifestaciones del Alto Duero", Espacio, Tiempo y Forma. Serie I. Prehistoria y Arqueología, Iv, pp. 241-268.

Gómez-Barrera, J. A. (1992): Grabados rupestres postpaleolíticos del Alto Duero. Soria: Museo Numantino y Caja Salamanca y Soria.

González, T. y Puente, A. (1991): "La cueva de La Peñona. La Concha de Villaescusa”. En Actas XX Congreso Arqueológico Nacional. Santander, pp. 315-321.

González Sainz, C. y González Morales, M. R. (1986): La Prehistoria en Cantabria. Historia General de Cantabria. I. Santander: Edic. Tantín.

Martínez Velasco, A. (2016): "Cueva de los Hornillos”. En Serna, M. L.; Martínez Velasco, A. y Fernández Acebo, V. (coords.): Después de Altamira. Arte y grafismo post-paleolitico en Cantabria. Santander: ACANTO, pp. 333-342.

Mas Cornellá, M. (2001): "Estructuras iconográficas e identificación de especies (secuencias iniciales y finales del arte postpaleolítico 'esquemático')", Cuadernos de Prehistoria, 22, pp. 147-182.

Moreno Gallo, M. A.; Delibes de Castro, G.; VIllalobos, R. y Basconcillos, J. (2020): Tumbas de gigantes. Dólmenes y túmulos en la provincia de Burgos. Burgos: Diput. Prov. de Burgos.

Ortega, A. I. y Martín Merino, M. A. (1986): "La arqueología del Karst de Ojo Guareña”. En Grupo Espeleológico Edelweiss (ed.): Monografia sobre Ojo Guareña. Kaite, 4-5. Burgos, pp. 331-389.

Ortega, A. I. y Martín Merino, M. A. (2013): Cuevas de Ojo Guareña. Una visión de la mano del Grupo Espeleológico Edelweiss. Burgos: Diput. Prov. de Burgos.
ORTEGA, J. (1974): La transformación de un espacio rural. Las montañas de Burgos: estudio de geografia regional. Valladolid: Univ. de Valladolid.

Peralta, E. (2000): Los cántabros antes de Roma. Madrid: RAH.

Pérez, C.; Sánchez C. y Viota, R. (2011): El Monte Hijedo. Un paraje natural por descubrir. Burgos: Ayto. de Alfoz de Santa Gadea.

Rincón, R. (1985): "Las Edades del Metal”. En García, M. A. (coord.): Historia de Cantabria. Prehistoria. Edades Antigua y Media. Santander: Edic. Estudio.

Rincón, R. (1993): "El Abrigo de Calderona, Ollero de Paredes Rubias (Palencia). Avance del estudio de los esquematismos rupestres en la Cantabria Antigua y las montańas de Palencia y Burgos", Publicaciones de la Institución Tello Téllez de Meneses, 64, pp. 35-180.

Royo, J. I. (2004): Arte rupestre de época ibérica. Grabados con representaciones ecuestres. Serie de Prehistòria i Arqueologia. Castellón: Diput. de Castellón.

Royo, J. I. (2005): "Las representaciones de caballos y de élites ecuestres en el arte rupestre de la Edad del Hierro de la Península Ibérica", Cuadernos de Prehistoria, 2, pp. 157-200.

Royo, J. I. (2009): "El arte rupestre de la Edad del Hierro en la Península Ibérica y su problemática: aproximación a sus tipos, contexto cronológico y significación", Salduie, 9, pp. 37-69.

Royo, J. I. y Campos, J. C. (2015): “Un nuevo conjunto de grabados al aire libre de cronología protohistórica e histórica, en el entorno del 'Castro Colorado' (Cuevas-Astorga, León)", Quaderns de Prehistoria y Arqueologia Castellonenses, 33, pp. 129-153.

Serna, M. L.; Martínez Velasco, A. y Fernández Acebo, V. (coords.) (2016): Después de Altamira. Arte y grafismo post-paleolitico en Cantabria. Santander: ACANTO.

Serna, M. L.; Martínez Velasco, A.; Fernández Acebo, V.; Castanedo, I. y Malpelo, B. (2016): "Presentación, justificación y ámbito. El otro arte rupestre en el centro de la cornisa cantábrica". En Serna, M. L.; Martínez Velasco, A. y FernánDeZ Acebo, V. (coords.): Después de Altamira. Arte $y$ grafismo post-paleolitico en Cantabria. Santander: ACANTO.

Sobrino, R. (1956): "Las representaciones antropomorfas de los petroglifos, en la costa atlántica euroafricana", Zephyrus, III, pp. 5-16.

Teira, L. C. y Ontañón, R. (1997): "Nuevas manifestaciones de arte esquemático en la comarca de Monte Hijedo (Burgos-Cantabria)". En De Balbín 
Behrmann, R. y Bueno, P. (eds.): II Congreso de Arqueología Peninsular, Tomo II-Neolítico, Calcolitico y Bronce. Zamora: Fundación Rei Alfonso Henriques, pp. 569-578.

Teira, L. C. y Ontañón, R. (2016a): "Estatua-estela de Salcedo (Valderredible) y los inicios del retrato social en la Prehistoria". En Serna, M. L.; Martínez Velasco, A. y Fernández Acebo,
V. (coords.): Después de Altamira. Arte y grafismo post-paleolitico en Cantabria. Santander: aCanto, pp. 44-51.

Teira, L. C. y Ontañón, R. (2016b): Arte esquemático en la Cueva de El Castillo". En Serna, M. L.; Martínez Velasco, A. y Fernández Acebo, V. (coords.): Después de Altamira. Arte y grafismo post-paleolitico en Cantabria. Santander: ACANTO, pp. 233-246. 